\title{
Application of Modern Digital Systems and Approaches to Business Process Management
}

\author{
Marija Zahar Djordjevic ${ }^{1, *(\mathbb{D}}$, Aleksandar Djordjevic ${ }^{1}\left(\mathbb{D}\right.$, Elena Klochkova $^{2}$ and Milan Misic $^{3}$ \\ 1 Faculty of Engineering, University of Kragujevac, 34000 Kragujevac, Serbia; adjordjevic@kg.ac.rs \\ 2 Institute of Humanities, Peter the Great St. Petersburg Polytechnic University, 195251 St. Petersburg, Russia; \\ samarinne@list.ru \\ 3 Higher Technical School of Professional Studies Zvečan, 38227 Zvečan, Serbia; milan.misic@pr.ac.rs \\ * Correspondence: marija.zahar@kg.ac.rs
}

Citation: Zahar Djordjevic, M.; Djordjevic, A.; Klochkova, E.; Misic, M. Application of Modern Digital Systems and Approaches to Business Process Management. Sustainability 2022, 14, 1697. https://doi.org/ $10.3390 /$ su14031697

Academic Editors: Ja-Shen Chen and Fabrizio D'Ascenzo

Received: 26 October 2021 Accepted: 27 January 2022

Published: 1 February 2022

Publisher's Note: MDPI stays neutral with regard to jurisdictional claims in published maps and institutional affiliations.

Copyright: (C) 2022 by the authors. Licensee MDPI, Basel, Switzerland. This article is an open access article distributed under the terms and conditions of the Creative Commons Attribution (CC BY) license (https:// creativecommons.org/licenses/by/ $4.0 /)$.

\begin{abstract}
In order to adapt to ever-changing customer needs and satisfy them, good Business Process Management (BPM) in Small and Medium-sized Enterprises (SMEs) is crucial. The target group of this research is production SMEs whose BPM can be monitored respecting the values of key performance indicators (KPIs). This paper shows how improving the performance of the observed business processes can improve the level of customer satisfaction. This improvement should lead to the sustainability of SMEs in the market. In this paper, evaluation of business processes performance is defined as a multi-criteria decision problem. The relative importance of considered KPIs and their imprecise values are described by linguistic expressions, which are then modeled by triangular intuitionistic fuzzy numbers (TIFNs). Calculation of KPI weights is done by using the fuzzy analytic hierarchy process (FAHP). Evaluation of BPM success is conducted respecting the obtained KPI weights and KPI values. An optimal solution for BPM success improvement, respecting customer satisfaction indicators, is calculated using the Artificial Neural Network (ANN) and Genetic Algorithm (GA) approaches. By applying the proposed model, managers of production SMEs can determine the management initiatives that will improve their business and the sustainability of their companies.
\end{abstract}

Keywords: business process management; SME; customer satisfaction; fuzzy logic; TIFNs; AHP; Artificial Neural Network; Genetic Algorithm

\section{Introduction}

Small and Medium-sized Enterprises (SMEs) present a driving force of economic development in many countries. According to [1], SMEs represent $99 \%$ of all businesses in the EU. In Serbia, this number is $99.8 \%$, employing $2 / 3$ of the total number of employees in the non-financial sector and participating with $32.8 \%$ in the formation of gross domestic product (GDP). However, the survival rate of SMEs is not high. In recent years, the number of SMEs that have survived the first two years of business in Serbia is around 60\% [2]. Production SMEs, which employ a vast number of people and significantly affect the overall growth of the economy, are especially vulnerable. To ensure their survival in the market, SMEs must successfully manage their business processes. It is very important that these enterprises continually improve their business processes, which leads to improved efficiency. The question is, what can help the managers of production SMEs in this situation? As SMEs have limited resources, the answer lies in Business Process Management (BPM) supporting models and software that would suit their needs. On the other hand, for the survival and success of these enterprises in the market, their focus on meeting customer needs is vital.

Until recently, organizations were concentrated only on the processes, focusing on how they operate, neglecting that the customer and their interaction to business processes are 
important [3]. However, according to [4], identification, analysis, and control of processes should be performed in convergence with customer experience, and not be addressed independently. These authors suggest that to achieve a great customer experience, excellent business processes are required. Convergence between these concepts may lead to many benefits: designing of business processes that enable customer expectations fulfillment, development of products and services that are needed by the customers, rational usage of organizational resources, and more. According to [5], BPM is an important factor in attaining high levels of customer satisfaction.

However, customer satisfaction is a complex issue [6]. According to [7], it refers to the level of customer satisfaction with products and after-sales services as well as the level of customer complaints. According to ISO 9000:2015 standard, customer satisfaction is "customer's perception of the degree to which the customer's expectations have been fulfilled" [8].

According to [9], customer satisfaction leads to their retention, and the transfer of satisfaction information leads to the acquisition of new customers. In this way, there is also an increase in market share and an increase in profitability because retaining customers is drastically more cost-effective than replacing them. Generally, customer satisfaction is one of the key indicators of business performance [10]. In a highly volatile market, such as the current-day market, with many competing companies offering similar products, customer satisfaction and loyalty are often seen as something that sets a company apart from the competition and is a critical element of business strategy.

In the literature, most of the papers dealing with determining customer satisfaction are related to service activities [6,11-18]. On the other hand, fewer papers focus on manufacturing companies [19-22], while a significant lack of literature has been noted regarding the link between the performance of their business processes and customer satisfaction.

Based on a review of the literature related to BPM, theoretical foundations, and empirical research related to the use of Artificial Neural Network (ANN) and Genetic Algorithm (GA), an integrated conceptual model has been developed to guide this research. The proposed model is used to find out whether it is possible to integrate ANN and GA to determine optimal business performance values that would result in improved customer satisfaction in certain business conditions.

ANN presents a powerful tool that can be used to model relationships in data sets that are nonlinear and highly correlated. Like real biological neural networks, ANNs are composed of interconnected, simple processing elements called artificial neurons. A neural network is a connected set of neurons or nodes. Like biological neurons, each ANN neuron receives input information, processes it, and delivers output information. The input can be a rough set of data or an output from another neuron, and the output may be the final result, or it may be the input for another neuron. In biological neurons and synapses, there are synaptic connections of different strengths, and these strengths are represented in the ANN neurons by the values of the weight coefficients. When processing information, artificial neurons in the ANN perform simultaneously and collectively, with the ability to learn, self-organize, and support robustness [23].

Since organizations always have to meet several different business goals, it is necessary to compromise, make optimal decisions, and not jeopardize any of the set goals in such situations. These goals can often conflict with each other, i.e., by reaching one goal an organization may move away from reaching another goal, and vice versa. Examples of conflicting goals are high quality and low cost, greater efficiency, and more excellent reliability. Due to the possibility of considering many factors that influence decision-making, a GA is a suitable method for finding optimal solutions. In the past few years, GA has been among the most exciting optimization techniques within artificial intelligence since modern technology has found a way to commercialize its application [24,25]. GA belongs to stochastic methods for finding optimal solutions [26] and is characterized by a significantly higher speed of finding solutions than classical methods and finding approximate optimal 
solutions in situations where classical methods cannot provide the precise optimal solution. It is particularly suitable for solving multi-criteria optimization problems [27].

GAs are well-known methods for the efficient search of complex spaces. Combining ANN for prediction and GAs to optimize business performance allows companies to improve business process management while reducing costs and increasing customer satisfaction. This approach gives SME managers important information regarding process parameter values, which are needed under different business conditions and different stages of the process to obtain the desired level of customer satisfaction indicators' values.

This paper is organized in the following way. The literature review is presented in Section 2, and the methodology and proposed algorithm are shown in Section 3. An illustrative example is presented in Section 4, and conclusions are given in Section 5.

\section{Literature Review}

This manuscript attempted to show how improving the performance of the observed business processes can improve the level of customer satisfaction. According to [28], the BPM paradigm could be considered as an integral part of almost all essential quality management paradigms (TQM, Standardized Management Systems such as ISO 9001, Lean, Six Sigma). These authors state that the integration of BPM into quality management systems and tools enables the development of effective and efficient organizations. Since the BPM is an integral part of the above-mentioned paradigms, we placed our focus on the connection of BPM and one of the key principles of SMS ISO 9001, focus on customers' satisfaction.

According to [28], the axis of the BPM philosophy and the implementation of its principles is the satisfaction of customers' needs. BPM assists managers of SMEs in achieving business objectives [29]. One of the most important business objectives is customers satisfaction. Key performance indicators (KPIs) as measurable values demonstrate how effectively a company is achieving key business objectives. Meaning that KPIs have crucial importance in the measurement and determination of target values. It is clear that achieving the desired target value is not possible without effectively implementing BPM [30]. Improving business processes performance is possibly be accomplished by monitoring and managing the KPIs of these processes [31]. Different studies are focused on business process improvement based on KPIs during the BPM [32,33].

However, determining the relative importance and values of KPIs is a difficult task because precise numbers cannot always present these variables. They often depend on the experience and opinion of decision-makers, so there are uncertainties in their determination. According to [34], uncertain and imprecise variables can be described by linguistic terms. Modeling of these linguistic terms can be done by using the theory of fuzzy sets $[35,36]$. Many papers deal with the modeling of linguistic variables. While several authors use type-1 fuzzy sets [37-40], other authors suggest using type-2 fuzzy sets [41-44] because of a higher degree of freedom and flexibility. In the previous research, there are many papers using intuitionistic fuzzy sets [45-47]. Although using intuitionistic fuzzy sets requires complex calculation, the authors of these papers claim that they present a better way of describing uncertainties that occur in modeling linguistic variables.

Different models for supporting BPM in SMEs have been developed in the previous studies based on fuzzy sets. These models allow managers to make decisions more quickly. In the paper [48], a fuzzy approach for evaluation of the quality of the purchasing process, respecting weights and values of KPIs for defined process' objectives, is presented. Using this approach, managers can identify gaps between existing and target conditions of process effectiveness, identify strengths and weaknesses, and improve purchasing process performance. In the papers $[49,50]$, fuzzy group decision-making problems for determining the weights of identified quality KPIs for the manufacturing process were considered. Ranking of manufacturing sub-processes and their KPIs was done by using a metaheuristic approach. These mathematical models enable quality evaluation of a production process, ranking, and optimization of KPIs using a GA. This approach enables managers of small and medium enterprises to improve successfully the production process quality. The 
authors in [51] used modified fuzzy analytic hierarchy process (FAHP) to obtain the fuzzy rank of business processes of a seaport. The assessment of the relative importance of each pair of performances and their KPIs are stated as a fuzzy group decision-making problem. The ranking of business processes is based on the overall preference index and the method for comparing fuzzy numbers. In [52], the authors were solving the problem of assessment and improvement of KPIs in the New Service Development Process. Determination of KPIs' weights was stated as a group decision-making problem. The ranking of KPIs was performed by using the GA approach. Determination of the management initiatives priority for the improvement of KPIs was based on fuzzy if-then rules and the singleobjective GA. This model enables identifying weak points in an enterprise and determining corrective measures that should lead to the improvement of the process performance. In [53], the authors developed a fuzzy model for ranking manufacturing sub-processes in the automotive industry, respecting the sub-processes' KPIs. This model, which uses the fuzzy extended ELECTRE III method for ranking considered sub-processes, enables improving quality management by assessing manufacturing sub-processes and their KPIs.

Mathematical models developed in all of these papers use triangular fuzzy numbers to deal with uncertainties in the considered problems. On the other hand, according to many authors $[45,54]$, intuitionistic fuzzy sets present a better way to model linguistic terms characterized by a degree of imprecision. These fuzzy sets [55] represent an extension of classical fuzzy set theory. Their fundamental characteristic is the existence of the nonmembership function and the membership function instead of standard fuzzy sets. One of the models for supporting BPM in SMEs, based on intuitionistic fuzzy sets, is shown in [56]. In that paper MCDM approach was used to rank production SMEs, respecting values and weights of KPIs of the production process. Modified TOPSIS method with triangular intuitionistic fuzzy numbers (TIFNs) was used while the benchmarking procedure was proposed to identify weaknesses in performance management and to choose appropriate improvement strategies. In [57] proposed model was extended to four processes, and a software solution for dealing with this problem was shown, which significantly shortens the time required to obtain a solution. In this paper, modeling of uncertainties is done using TIFNs, while modern artificial intelligence techniques and approaches, like ANN and GA, are used to establish a link between business processes performance in manufacturing SMEs and customer satisfaction.

ANNs have proven to be a promising computing system in many forecasting and business applications due to their ability to learn from data sets, their nonparametric nature (i.e., no rigid assumptions), and their ability to generalize [58]. Their application is widely used in business performance [59], most recent internet financing [60], performance management [61], and online education and teaching evaluation system performance predictions [62]. The authors in [59] used ANN as the prediction system to predict e-business performance for the Chinese service industry. In their study, for the backpropagation (BP) ANN model, the inputs are the data of e-business performance measured by a five-point Likert scale, and the expected outputs of training neural network come from cluster analysis. The results showed that the prediction system is reliable and accurate; and that it can be used for evaluating enterprise performance effectively. In [63], authors compared ANN and multiple linear regression (MLR) prediction performance on reliability of accounting information system as independent variables and business performance as a dependent variable prediction model and revealed that in terms of predictive accuracy test, the ANN has higher accuracy than regression analysis. In [60], the author presented the application of the BP ANN method to analyze the risks of Internet finance in terms of market, law, credit, personal information, and professional knowledge. The same authors stated that BP ANN had an excellent prediction effect. According to [62], a combination of GA and ANN has given good optimal results for social science research performance evaluation in colleges and universities. Similar research was conducted in [61], where authors proposed a performance index system for university social science research based on BP ANN and the relevant theoretical knowledge. The presented BP ANN models have shown meager error 
value and good generalization abilities, which effectively demonstrates that the training sample data can ideally fit the neural network simulation. In the same way, it shows that the output value of the BP ANN can be very close to the input vector.

GA has been applied and provided acceptable optimal results in many problems: process scheduling problems [64], system parameter determination problems [65], data mining process optimization [66], and KPI value optimization [49,52]. In [64], authors proposed a self-learning GA (SLGA) which adopts GA as the primary optimization method, with its key parameters intelligently adjusted based on reinforcement learning (RL). The same authors compared the learning effect and performance of SLGA in solving the Flexible Job Shop Problem (FJSP) with other algorithms using two groups of benchmark data instances with different scales. Their experiment results show that the proposed SLGA significantly outperforms its competitors in solving FJSP. In [65], the GA-based two-step classification method is proposed, which allows selecting the significant factors and adapting the model itself to application in bankruptcy forecasting, improving the advantages and alleviating the weaknesses inherent in standard classifiers enabling the business decisions to support with higher reliability. In [66], new ensemble data mining techniques that involve an adaptive neuro-fuzzy inference system (ANGIS) with GA for landslide spatial modeling have been presented, showing that the proposed ensemble data mining techniques can be applied for land use planning and management of landslide susceptibility and hazard. Literature resources show that GA has its application in obtaining optimal values within the production process KPIs, the ranking of KPIs, and provides the basis for successful improvement of the production process quality $[49,67]$. Furthermore, the ranking and improvement of the new service development process KPI values problem could be stated as a multi-criteria decision-making problem that the GA could solve [52]. It can be concluded that GAs has provided scheduling, trend tracking, and finding optimal performance values in various fields and that they can be used to find the optimal solution in many scientific and industrial fields.

\section{Methodology}

This paper intends to assess optimal improvements for BPM in SMEs, which should lead to increasing the level of customer satisfaction. In order to achieve this, KPIs for each business process must be defined. Since there are no standards that define the most appropriate KPIs for each business process, it is common practice to determine KPIs based on the literature data and the results of good practice. The first issue that arises in this problem relates to the assessment of the relative importance of KPIs. The second issue relates to the determination of the KPIs' values. The problem is significantly more complex because the realistic assumption is that the considered variables are not measurable so linguistic terms will describe them.

In this paper, linguistic variables are modeled using the TIFNs that belong to intuitionistic fuzzy sets [55]. Assessments of the relative importance of KPIs for each business process are stated by fuzzy pair-wise comparison matrix, an analogy to Analytic Hierarchy Process (AHP) method. According to [68], this method is very transparent and easy to understand. The AHP method [69] has been widely used for various decision-making problems. Its extensions have been applied in numerous papers, for example, FAHP with Triangular fuzzy numbers, developed in [70] and used in [71,72]; FAHP with Trapezoidal fuzzy numbers applied in [73,74]; FAHP with the interval type-2 triangular or trapezoidal fuzzy numbers used in [75,76]; FAHP with TIFNs developed in [77] and used in [68,78-81], etc.

In this paper, to determine the weights of KPIs, decision-makers estimate the relative importance of KPIs. Since the calculated weights of KPIs depend on the assessment of decision-makers, it is very important that these decision-makers have sufficient knowledge, such as quality management auditors, or managers with a lot of experience. They use linguistic expressions modeled by TIFNs (Table 1), as shown in [57]. Domains of these TIFNs are defined on the interval from 1 to 5 . To determine the relative importance of KPIs, value 'one' means equal importance, and value 'five' means extremely important. 
Table 1. Linguistic expressions for the relative importance of KPIs.

\begin{tabular}{cc}
\hline Relative Importance & TIFN \\
\hline Slightly more important & $\widetilde{\mathrm{A}} 1=\{(1,1.5,2),(1,1.5,2.3)\}$ \\
A bit more important & $\widetilde{\mathrm{A}} 2=\{(1,2,3),(1,2,3.3)\}$ \\
More important & $\widetilde{\mathrm{A}} 3=\{(2,3,4),(1.8,3,4.2)\}$ \\
Strongly more important & $\widetilde{\mathrm{A}} 4=\{(3,4,5),(2.7,4,5)\}$ \\
Absolutely more important & $\widetilde{\mathrm{A}} 5=\{(4,5,5),(3.7,5,5)\}$ \\
\hline
\end{tabular}

According to the conventional AHP method, consistency checking should be performed, ensuring the entered data's consistency. Since the problem analyzed in this paper is a group decision-making problem, KPI weights are calculated using the fuzzy geometrical mean method and then aggregated using the fuzzy averaging operator.

On the other hand, decision-makers (managers above all) of each SME involved in determining optimal values of BPM success estimate KPI values for each business process. The imprecisions related to the assessment of KPI values are described by linguistic expressions modeled by TIFNs, as shown in Table 2, according to [57]. Domains of TIFNs describing these imprecisions are defined on the interval from 1 to 9 .

Table 2. Linguistic expressions for KPIs' values.

\begin{tabular}{cc}
\hline Value of KPI & TIFN \\
\hline Very low value & $\widetilde{v} 1=\{(1,1,2),(1,1,2.3)\}$ \\
Low value & $\widetilde{v} 2=\{(1,2,3),(1,2,3.3)\}$ \\
Almost low value & $\widetilde{v} 3=\{(2.5,3.5,4.5),(2.3,3.5,4.7)\}$ \\
Middle value & $\widetilde{v} 4=\{(4,5,6),(3.8,5,6.2)\}$ \\
Fairly high value & $\widetilde{v} 5=\{(5.5,6.5,7.5),(5.3,6.5,7.7)\}$ \\
High value & $\widetilde{v} 6=\{(7,8,9),(6.7,8,9)\}$ \\
Very high value & $\widetilde{v} 7=\{(8,9,9),(7.7,9,9)\}$ \\
\hline
\end{tabular}

Based on the aggregated weights and the estimated values of KPIs, current ratings of BPM success at the level of each business process are calculated, as shown in Section 3.1.

When it comes to monitoring customer satisfaction, specific indicators also must be defined, and in this paper, it is assumed that their importance is equal. This allows these indicators to be observed and improved at once. In case the observed company has a desire to observe and improve only one indicator, for example, which it considers to be the most important at the moment, the input data for ANN and GA will contain only data for that indicator. Their values are also estimated by decision-makers of each involved SME and described by linguistic terms shown in Table 2 .

Based on the calculated BPM success ratings, an ANN model is then developed to predict the values of satisfaction indicators in a specific SME. A GA then uses the trained ANN model to determine the BPM parameter values that would result in optimal satisfaction indicator values obtained in various operating conditions.

GA optimizes goals using objective functions and constraints to find the optimal solution in the domain of possible solutions. Objective functions and defined constraints are usually in conflict, so solutions have acceptable values instead of optimal values for all goals. Unlike the optimization of one objective function (single-criteria optimization), with usually only one obtained optimal solution, in multi-criteria optimization, with more target functions to be satisfied, the number of resulting solutions is significantly higher (trade-offs). Multicriteria optimization consists of two phases. In the first phase, the given target functions are optimized, and solutions are obtained in the form of a Pareto front (set), while in the second phase, a decision is made on the specific solution to be selected from the Pareto set. The Pareto set is a set of mutually non-dominant solutions, so the final decision is up to the decision-maker. For Pareto solutions, the property is that they are harmonized based on dominance. Dominance refers to the fact that some solution A is 
dominant over solution B, if it has a more optimal value concerning solution B for at least one objective function, and it does not have a higher value for other objective functions.

Using the fuzzy algebra rules [82,83], ANN and GA approaches, the links between BPM success and customer satisfaction indicators can be found. Based on that, the optimal values for BPM parameters are determined while maximizing the values of customer satisfaction indicators. Since ANN and GA are used in the proposed algorithm, the obtained results largely depend on the number of observed SMEs and entered values. By determining the gaps between current and optimal values of BPM success, the management team of each SME can conclude which business process requires performance improvement.

\subsection{The Proposed Algorithm}

This section presents the 17-step procedure for evaluating optimal BPM improvements in SMEs, respecting the values and weights of KPIs. The presented algorithm intends to provide theoretical background for the development of software solutions. Using this solution, SMEs could have tools for fast and efficient insight on their process as well as a tool that will detect the major gaps between existing situations and optimal situations. This will provide a useful tool to SMEs that was available, until now, only for the large systems.

Step 1 . The fuzzy pair-wise comparison matrix of the relative importance of KPIs $i, i^{\prime}$ on the level of each business process $p$ are stated, based on the assessments of each expert $q$ :

$$
\left[\widetilde{w}_{i i^{\prime}}^{q p}\right] ; i, i^{\prime}=1, \ldots, I ; p=1, \ldots, P ; q=1, \ldots, Q
$$

Step 2. In order to check consistency, the defuzzification procedure is temporarily applied [84]:

$$
\operatorname{defuzz}\left(\widetilde{w}_{i i^{\prime}}^{q p}\right)=\frac{\left(\widetilde{w}_{i i^{\prime} 1}^{q p}+2 * \widetilde{w}_{i i^{\prime} 2}^{q p}+\widetilde{w}_{i i^{\prime} 3}^{q p^{\prime}}\right)+\left(\widetilde{w}_{i i^{\prime} 1}^{q p^{\prime}}+2 * \widetilde{w}_{i i^{\prime} 2}^{q p}+\widetilde{w}_{i i^{\prime} 3^{\prime}}^{q p}\right)}{8}
$$

Step 3. Consistency is performed according to the procedure presented in [69]. If the consistency index of each given matrix is $<10 \%$, it is considered that the matrix is consistent, and no corrections are necessary.

Step 4. Weights of each KPI $i$, at the level of each expert $q$ and at the level of each business process $p$ are calculated using the methodology shown in [68]:

$$
\widetilde{w}_{i}^{q p}=\frac{\widetilde{m}_{i}^{q p}}{\sum_{i=1}^{I} \widetilde{m}_{i}^{q p}}
$$

where $\widetilde{m}_{i}^{q p}$ is calculated as geometric mean:

$$
\widetilde{m}_{i}^{q p}=\sqrt[I]{\widetilde{w}_{i 1}^{q p} \cdot \ldots \cdot \widetilde{w}_{i I}^{q p}} ; i=1, \ldots, I ; p=1, \ldots, P ; q=1, \ldots, Q ;
$$

Step 5. By using the fuzzy averaging operator, aggregated values of the weights of each KPI $i$, at the level of each business process $p$, are determined:

$$
\widetilde{w}_{i}^{p}=\frac{1}{Q} \cdot \sum_{q=1}^{Q} \widetilde{w}_{i}^{q p} ; i=1, \ldots, I ; p=1, \ldots, P ; q=1, \ldots, Q
$$

Figure 1 shows the steps of the proposed algorithm. 


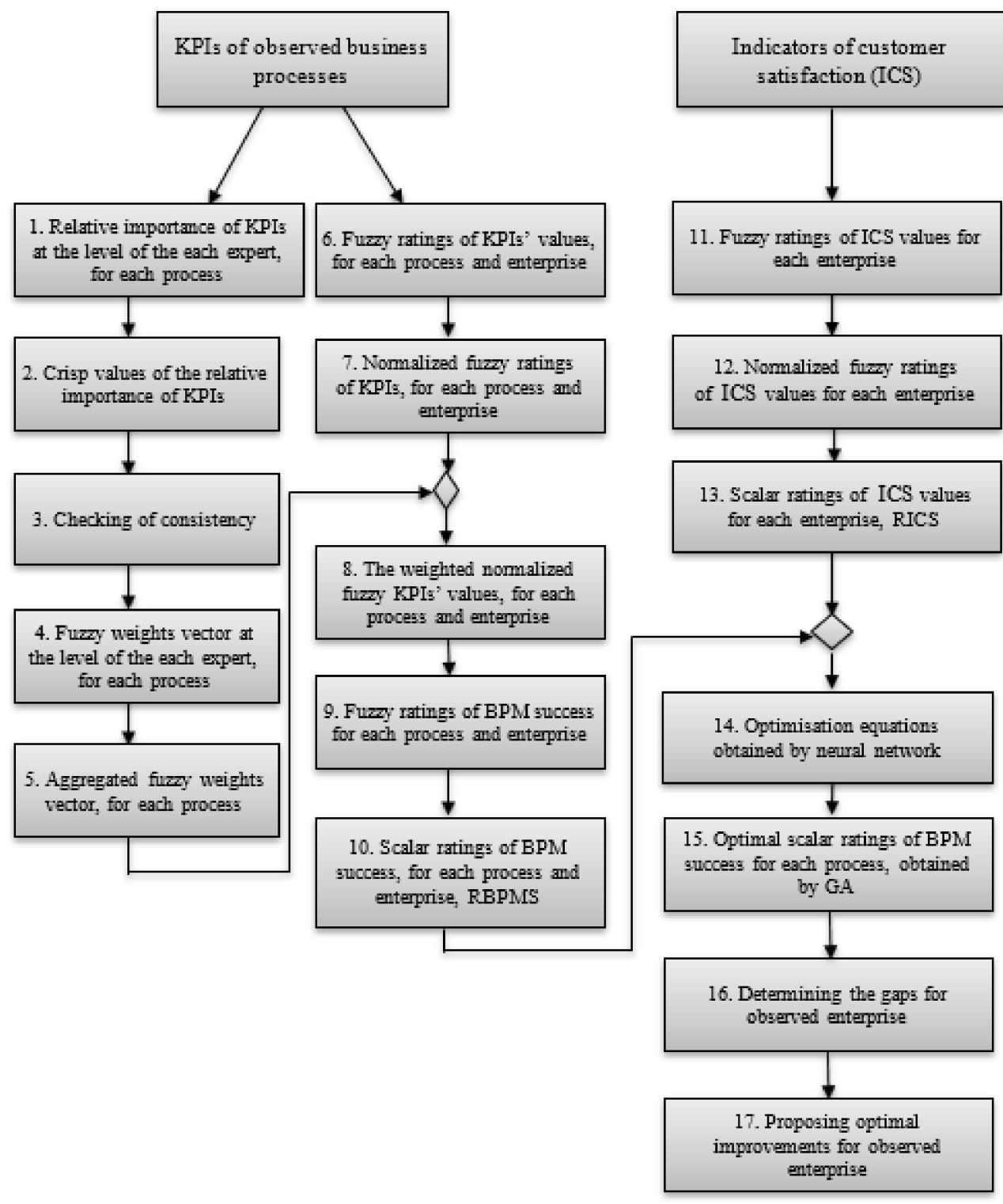

Figure 1. Steps of the proposed algorithm.

Step 6. Using predefined linguistic statements, decision-makers within each enterprise $e$ estimate the fuzzy ratings of KPIs' values for each process $p, \widetilde{v}_{i}^{e p}$.

Step 7. Fuzzy ratings of values of KPIs are normalized using the linear normalization procedure [85], for benefit-type and cost-type of KPIs, respectively:

$$
\begin{aligned}
& \widetilde{r}_{i}^{e p}=\left\{\left(\frac{v_{i 1}^{e p}}{v_{3}^{+}}, \frac{v_{i 2}^{e p}}{v_{3}^{+}}, \frac{v_{i 3}^{e p}}{v_{3}^{+}}\right),\left(\frac{v_{i 1}^{e p \prime}}{v_{3}^{+}}, \frac{v_{i 2}^{e p}}{v_{3}^{+}}, \frac{v_{i 3}^{e p \prime}}{v_{3}^{+}}\right)\right\} \\
& \widetilde{r}_{i}^{e p}=\left\{\left(\frac{v_{1}^{-}}{v_{i 3}^{e p}}, \frac{v_{1}^{-}}{v_{i 2}^{e p}}, \frac{v_{1}^{-}}{v_{i 1}^{e p}}\right),\left(\frac{v_{1}^{-}}{v_{i 3}^{e p}}, \frac{v_{1}^{-}}{v_{i 2}^{e p}}, \frac{v_{1}^{-}}{v_{i 1}^{e p \prime}}\right)\right\}
\end{aligned}
$$

where: $v_{3}^{+}=\max \left\{v_{i 3}^{e p}\right\}, v_{1}^{-}=\min \left\{v_{i 1}^{e p}\right\}, i=1, \ldots, I ; e=1, \ldots, E ; p=1, \ldots, P$.

Step 8. The weighted normalized fuzzy KPIs' values, within the enterprise $e$, for each process $p$, are calculated as:

$$
\widetilde{d}_{i}^{e p}=\widetilde{w}_{i}^{p} \cdot \widetilde{r}_{i}^{e p} ; i=1, \ldots, I ; e=1, \ldots, E ; p=1, \ldots, P
$$


Step 9. Fuzzy ratings of BPM success at the level of each business process $p$, for each enterprise $e$, are calculated as:

$$
\widetilde{O}^{e p}=\frac{\sum_{i=1}^{I} \widetilde{d}_{i}^{e p}}{I} ; i=1, \ldots, I ; e=1, \ldots, E ; p=1, \ldots, P
$$

Step 10. By using the defuzzification procedure (step 2 of the algorithm), scalar ratings of BPM success (RBPMS) for each process within each enterprise are obtained:

$$
R B P M S^{e p}=\operatorname{defuzz}\left(\widetilde{O}^{e p}\right)
$$

Step 11. Using predefined linguistic statements, decision-makers within each enterprise $e$ estimate the fuzzy ratings of the indicators of customer satisfaction (ICS): $\widetilde{v}_{i}^{e} ; i=1, \ldots$, $I ; e=1, \ldots, E$.

Step 12. By using the linear normalization procedure (step 7 of the algorithm), these ratings become comparable: $\widetilde{r}_{i}^{e} ; i=1, \ldots, I ; e=1, \ldots, E$.

Step 13. By using the defuzzification procedure (step 2 of the algorithm), scalar ratings of ICS, for each enterprise $e$, are obtained: $R I C S_{i}^{e} ; i=1, \ldots, I ; e=1, \ldots, E$.

Step 14. Applying neural network to obtain optimization equations based on the scalar ratings of the observed indicators' values (RICS) as dependent variables and scalar ratings of BPM success (RBPMS) as independent variables:

$$
f\left([R I C S]_{I x E}\right)=\text { pureline }\left(\left[L W^{2,1}\right]_{I x 10} x\left(\operatorname{tansig}\left(\left[I W^{1,1}\right]_{10 x I}\left[R B P M S^{1}\right]_{I x E}+\left[b^{1}\right]_{10 x 1}\right)\right)+\left[b^{2}\right]_{I x 1}\right)
$$

where $E$ represents the overall number of considered enterprises, $I$ is the overall number of ICS, while $I W^{1,1}, L W^{2,1}, b^{1}$ and $b^{2}$ present matrixes of the weights vectors and biases in the two-layered neural network, respectively.

Step 15. Applying GA to obtain optimal RBPMS based on the equations derived from the previous step and the desired level of observed customer satisfaction indicators:

$$
\max \left(f\left(\left[\operatorname{RICS}^{*}\right]_{I x M}\right)\right)=\text { pureline }\left(\left[L W^{2,1}\right]_{I x 10} x\left(\operatorname{tansig}\left(\left[I W^{1,1}\right]_{10 x I}\left[R B P M S^{1 *}\right]_{I x M}+\left[b^{1}\right]_{10 x 1}\right)\right)+\left[b^{2}\right]_{I x 1}\right)
$$

where $\left[R B P M S^{1 *}\right]_{I x M}$ present the proposed optimal values in order to achieve desired levels of $\left[\text { RICS }^{*}\right]_{I x M}$ and $M$ presents the overall number of obtained optimal solutions.

Step 16. Determining the gaps between current and optimal RBPMS for each process within the observed enterprise.

Step 17. Proposing optimal improvements for observed enterprise, based on the ranking of gaps.

\section{Illustrative Example}

As well as in other countries of the world, manufacturing SMEs operating in Serbia gain a significant role in the country's economy. This is why the proposed algorithm's application is tested on data given from 30 manufacturing SMEs operating in this country. These companies belong to the sector of the metal processing industry, which is very important for the development of Serbia. In accordance with [57], four key business processes for manufacturing SMEs which are observed in this paper are: (1) purchasing process, (2) production process, (3) marketing and sales process, and (4) after-sales service process. In compliance with the existing literature and the results of good practice, KPIs for each of these processes (Table 3) were determined. 
Table 3. KPIs of observed business processes [57]. Sources from the one of the author's dissertation.

\begin{tabular}{|c|c|c|c|c|}
\hline & Purchasing & Production & Marketing and Sales & $\begin{array}{c}\text { After-Sales } \\
\text { Service Process }\end{array}$ \\
\hline$i=1$ & $\%$ of complete orders & $\begin{array}{l}\text { Number of complaints } \\
\text { due to } \\
\text { non-compliance/total } \\
\text { number of complaints } \\
\text { (in \%) }\end{array}$ & $\begin{array}{l}\% \text { of realization of sales } \\
\text { plan (quantity) }\end{array}$ & $\begin{array}{l}\% \text { of complaints resolved } \\
\text { in time }\end{array}$ \\
\hline$i=2$ & $\%$ of late purchases & $\begin{array}{l}\% \text { of product } \\
\text { incompetence }\end{array}$ & $\%$ of offers completed & $\%$ of complaints approved \\
\hline$i=3$ & $\%$ inconsistent quality & $\begin{array}{l}\% \text { of production plan } \\
\text { realization (quantity) }\end{array}$ & $\%$ of late deliveries & $\%$ of recurring complaints \\
\hline$i=4$ & $\begin{array}{c}\text { Non-compliance } \\
\text { costs / total procurement } \\
\text { costs (in } \%)\end{array}$ & $\%$ of the cost of scrap & $\begin{array}{c}\text { \% of marketing } \\
\text { campaigns that did not } \\
\text { start in time }\end{array}$ & $\begin{array}{l}\% \text { of phone calls } \\
\text { answered in time }\end{array}$ \\
\hline$i=5$ & $\begin{array}{l}\text { Time from procurement } \\
\text { request to contract signing }\end{array}$ & $\begin{array}{l}\text { Time of unplanned } \\
\text { delays/total production } \\
\text { cycle time }\end{array}$ & $\begin{array}{l}\text { Completeness of market } \\
\text { research information }\end{array}$ & \\
\hline$i=6$ & & & $\begin{array}{c}\text { Market research } \\
\text { costs/total marketing and } \\
\text { sales costs }\end{array}$ & \\
\hline
\end{tabular}

On the other hand, the observed indicators of customer satisfaction, determined in the same way, are: (1) degree of fulfillment of customer requirements, (2) customer satisfaction with quality, (3) customer loyalty, and (4) customer satisfaction with the implementation of the contract. Customer requirements are the desired characteristics of products that should be met in order that the customer will decide to purchase the product. Satisfaction with product quality refers to products' technical and functional characteristics that are subject to complaints [86]. Customer loyalty represents the degree of customers retention [87], while satisfaction with the implementation of the contract refers to all the elements specified in the sales contract, which the company is obliged to fulfill. It is assumed that the importance of these indicators is equal.

Data collection was performed by collecting filled-up questionnaires, as shown in [57]. In order to determine the weights of KPIs, for each process, six experts q were engaged. Their fuzzy assessments of the relative importance of KPIs are shown in [57]. Furthermore, in the mentioned work, input data for the KPIs' values are given, based on the assessments of managers from each of 30 SMEs. These assessments are presented in Appendix A. In order to evaluate the values of indicators of customer satisfaction, data in Appendix B were collected, also based on the assessments of managers.

Based on the collected data, the proposed algorithm is tested.

\section{Demonstration of the Algorithm}

Figure 2 presents the fuzzy pair-wise comparison matrix of the relative importance of KPIs for the purchasing process, assessed by expert $q=4$. He gave his statement based on his knowledge and experience (Step 1 of the Algorithm). Here, the decision-maker used five predefined linguistic expressions which were modeled by TIFNs. 


\begin{tabular}{|c|c|c|c|c|c|}
\hline & $i^{\prime}=1$ & $i^{\prime}=2$ & $i^{\prime}=3$ & $i^{\prime}=4$ & $i^{\prime}=5$ \\
\hline$i=1$ & 1 & $\widetilde{\mathrm{A}}_{2}$ & $1 / \widetilde{\mathrm{A}}_{2}$ & $1 / \widetilde{\mathrm{A}}_{2}$ & $\widetilde{\mathrm{A}}_{2}$ \\
\hline$i=2$ & $1 / \widetilde{\mathrm{A}}_{2}$ & 1 & $1 / \widetilde{\mathrm{A}}_{3}$ & $1 / \widetilde{\mathrm{A}}_{3}$ & 1 \\
\hline$i=3$ & $\widetilde{\mathrm{A}}_{2}$ & $\widetilde{\mathrm{A}}_{3}$ & 1 & 1 & $\widetilde{\mathrm{A}}_{3}$ \\
\hline$i=4$ & $\widetilde{\mathrm{A}}_{2}$ & $\widetilde{\mathrm{A}}_{3}$ & 1 & 1 & $\widetilde{\mathrm{A}}_{3}$ \\
\hline$i=5$ & $1 / \widetilde{\mathrm{A}}_{2}$ & 1 & $1 / \widetilde{\mathrm{A}}_{3}$ & $1 / \widetilde{\mathrm{A}}_{3}$ & 1 \\
\hline
\end{tabular}

Figure 2. Fuzzy pair-wise comparison matrix for the purchasing process.

After that, for each element of the stated fuzzy pair-wise comparison matrices, defuzzification was performed to check the consistency of the entered data (Step 2 of the Algorithm). The defuzzification method is illustrated in an example of the TIFN $\tilde{\mathbf{A}}_{3}$.

$$
\operatorname{defuzz}\left(\tilde{\mathbf{A}}_{3}\right)=\frac{(2+2 * 3+4)+(1.8+2 * 3+4.2)}{8}=3
$$

In the same way, scalar values of other elements of the fuzzy pair-wise comparison matrices were calculated. An example of obtained pair-wise comparison matrix with scalar values is given in Figure 3.

\begin{tabular}{|c|c|c|c|c|c|}
\hline & $i^{\prime}=1$ & $i^{\prime}=2$ & $i^{\prime}=3$ & $i^{\prime}=4$ & $i^{\prime}=5$ \\
\hline$i=1$ & 1 & 2.0375 & 0.5795 & 0.5795 & 2.0375 \\
\hline$i=2$ & 0.5795 & 1 & 0.3596 & 0.3596 & 1 \\
\hline$i=3$ & 2.0375 & 3 & 1 & 1 & 3 \\
\hline$i=4$ & 2.0375 & 3 & 1 & 1 & 3 \\
\hline$i=5$ & 0.5795 & 1 & 0.3596 & 0.3596 & 1 \\
\hline
\end{tabular}

Figure 3. Pair-wise comparison matrix for the purchasing process.

Using the existing procedure Consistency Index was calculated (Step 2 of the Algorithm). Its value is 0.05 , so this matrix may be considered consistent, and it is not necessary to re-evaluate the relative importance of KPIs. In the same way, the consistency of other pair-wise comparison matrices was checked.

By using Step 4 of the Algorithm, the weight of KPI $i=1$ of the purchasing process $(p=1)$, at the level of expert $q=4$, was calculated as:

$$
\widetilde{w}_{1}^{41}=\frac{\widetilde{m}_{1}^{41}}{\sum_{i=1}^{5} \widetilde{m}_{i}^{41}}=\{(0.087,0.1758,0.369),(0.0805,0.1758,0.3993)\}
$$

where $\widetilde{m}_{1}^{41}=\{(0.6444,1,1.5519),(0.6203,1,1.6122)\}$.

In the same way, weights of the rest considered KPIs, obtained by each expert, are calculated at each business process level.

By applying Step 5 of the proposed Algorithm, aggregated weights of each KPI at the level of each business process are obtained (Appendix $C$ ). In accordance with this, the weight of KPI $i=1$ for process $p=1$ is calculated as:

$$
\widetilde{w}_{1}^{1}=\{(0.1720,0.3274,0.5771),(0.1581,0.3274,0.6328)\}
$$

In Step 6, fuzzy assessments of the KPIs' values, at the level of each business process, were estimated by decision-makers of each enterprise using seven predefined linguistic expressions which were modeled by TIFNs (Appendix A).

The application of Step 7 of the proposed Algorithm is illustrated by the example: let the value of KPI $(i=1)$ at the level of business process $p=1$ in enterprise $e=1$ be described by TIFN:

$$
\widetilde{v}_{1}^{11}=\{(7,8,9),(6.7,8,9)\}
$$


The normalized value of this benefit-type KPI is calculated as:

$$
\widetilde{r}_{1}^{1}=\left\{\left(\frac{7}{9}, \frac{8}{9}, \frac{9}{9}\right),\left(\frac{6.7}{9}, \frac{8}{9}, \frac{9}{9}\right)\right\}=\{(0.7778,0.8889,1),(0.7444,0.8889,1)\}
$$

In the same way, normalized values of all KPIs for all business processes in each enterprise were calculated.

Using Step 8 of the Algorithm, the weighted normalized values of all KPIs for each business process in each enterprise were calculated. An example illustrates this for KPI $i=1$ of process $p=1$ in enterprise $e=1$ :

$$
\begin{aligned}
& \widetilde{d}_{1}^{11}=\widetilde{w}_{1}^{1} \cdot \widetilde{r}_{1}^{11}=\quad\{(0.1720,0.3274,0.5771),(0.1581,0.3274,0.6328)\} \\
&=\{(0.1338,0.2910,0.5771),(0.1177,0.2910,0.0 .6328)\}
\end{aligned}
$$

In the same way, the weighted normalized values of all other KPIs are calculated.

After that, fuzzy ratings of BPM success at each enterprise's level of each business process are calculated using Step 9 of the Algorithm. Obtained fuzzy rating for process $p=1$ in enterprise $e=1$ is:

$$
\widetilde{O}^{11}=\{(0.0631,0.1826,0.3599),(0.0528,0.1826,0.3916)\}
$$

Finally, using the defuzzification procedure (Step 10) representative scalar of this rating is obtained:

$$
\text { RBPMS }^{11}=0.1997
$$

In the same way, scalar ratings of BPM success at the level of each business process for each enterprise are calculated. These ratings are later used as input data to obtain optimization equations (Appendix B).

In Step 11 decision-makers assess ICS, using predefined linguistic statements, which are then modeled by TIFNs. Let the first ICS $i=1$, in the enterprise $e=1$, be described by the linguistic expression "High value". This expression is then modeled as TIFN:

$$
\widetilde{v}_{1}^{1}=\{(7,8,9),(6.7,8,9)\}
$$

In Step 12 of the Algorithm, this value is normalized and calculated as shown in Step 7, so the obtained result is:

$$
\widetilde{r}_{1}^{1}=\{(0.7778,0.8889,1),(0.7444,0.8889,1)\}
$$

By using the defuzzification procedure in Step 13 scalar rating of ICS $i=1$, for enterprise $e=1$, is calculated:

$$
\operatorname{RICS}_{1}^{1}=0.8847
$$

In the same way, the RICS of all indicators in all enterprises are calculated, and they also present input data for obtaining the optimization equations (Appendix B).

In Step 14, ANN is used to obtain optimization equations based on the RICS $S_{i}^{e}$ as dependent variables, and $R B P M S^{e p}$ as independent variables, $i=1, \ldots, I ; e=1, \ldots, E ; p=1$, ... P. A backpropagation ANN with two layers is used, and appropriate weights and biases are calculated, as shown in Appendix C.

In Step 15 of the Algorithm, the limits of all RICS values are set to be 0.97 , as it is the maximum value of RICS. The goal is to achieve the optimal scores for all RICS at once, which is as close as possible to the value of 0.97. By using the GA, optimal RBPMS for each process are obtained (Appendix D). It can be seen that there are nine solutions, and in this example, the final solution (see Table 4) was chosen as optimal because it has the highest scores of all RICS observed. 
Table 4. Chosen solution.

\begin{tabular}{cccccccc}
\hline & \multicolumn{3}{c}{ Optimal RBPMS } & \multicolumn{3}{c}{ RICS } \\
\hline$p=1$ & $p=2$ & $p=3$ & $p=4$ & $i=1$ & $i=2$ & $i=3$ & $i=4$ \\
\hline 0.4976 & 0.1451 & 0.3559 & 0.9864 & 0.857691 & 0.948955 & 0.78133 & 0.899164 \\
\hline
\end{tabular}

Based on the results obtained, each enterprise can identify gaps between current and optimal RBPMS values for each process (Step 16). The results for the enterprise $e=23$ are shown in Figure 4. $\mathrm{n}$ the same way, scalar values of other el

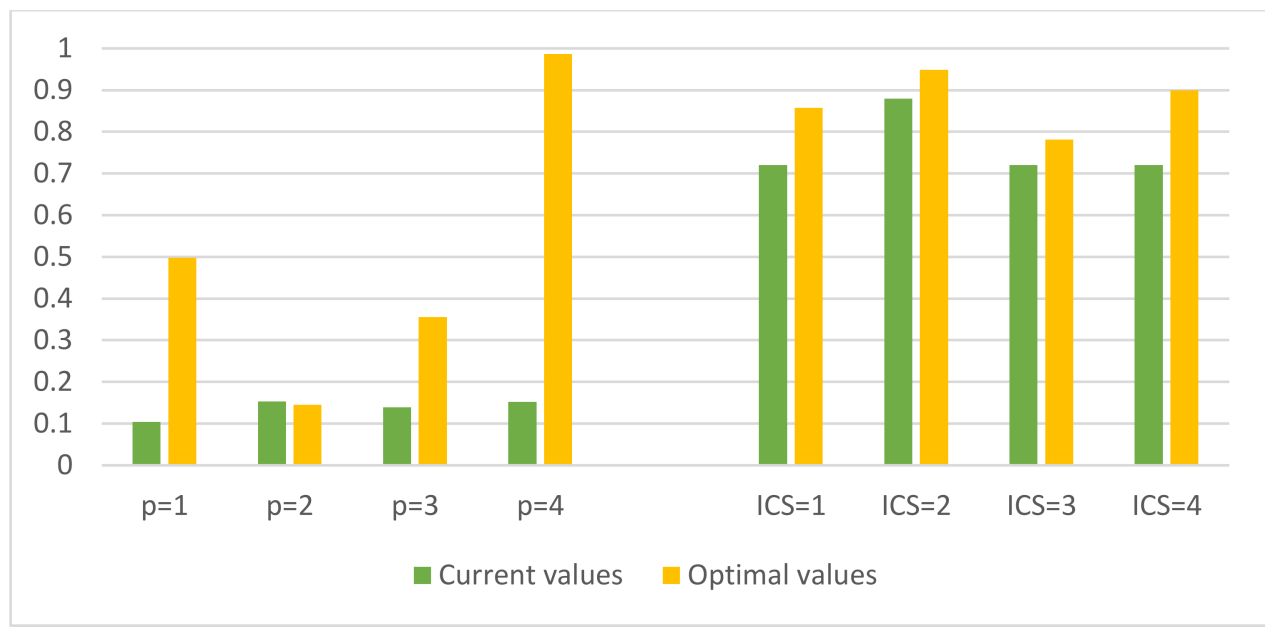

Figure 4. Results for enterprise $e=23$.

Based on Figure 4, managers of SME $e=23$ can see that the highest gap between the current and optimal values is for processes $p=4$, i.e., after-sales service process, and this means that this process needs the greatest improvements. On the other hand, it is seen that the production process $(p=2)$ does not need improvement. According to the enterprise's strategy, managers of this SME should decide which methods of the business processes improvement will be applied (Step 17 of the Algorithm). There are different possibilities, depending on their opinions and available resources.

In order to improve the process with the highest gap, managers of this SME can be focused on the calculated weights of KPIs for the after-sales service process, obtained in Step 5 of the Algorithm. The most important KPI is “\% of complaints resolved in time", which is a benefit type KPI. It means that corrective actions may firstly be aimed to increase the value of that KPI. In order to improve this indicator, business managers of the observed SME should consider whether it is necessary to increase the number of employees involved in resolving complaints or perhaps to carry out their additional training. After that, the manager may focus on the improvements of other KPIs. These improvements can be realized through better communication with customers and proper execution of complaints, respecting all customer requirements, their advice, and suggestions in accordance with service recovery practice.

After that, the decision-makers of SME $e=23$ can decide to implement strategies that should improve the purchasing process. In this process, the most important KPI is "\% of complete orders", a benefit type KPI the value of which should be increased. This can be achieved by choosing suppliers who have a better reputation and who are more responsible towards their associates. Managers can also focus their attention on other KPIs, but since those KPIs refer to the quality and time for which the suppliers are responsible, the best way for the KPIs improvement is to carry out the process of evaluation, ranking, and selection of appropriate suppliers correctly.

In the end, looking at the obtained results, it can be seen that KPI with the most significant importance for the marketing and sales process is "\% of realization of sales 
plan (quantitative)". It means that corrective actions may first be aimed to increase the value of this KPI. This can be done by aligning the sales plan with realistic possibilities, improving marketing activities, and using new forms of promotion. Other ways to improve this process are more careful planning of marketing activities, including determining the promoter, the order in which promotions are performed, the number of funds required, improving product delivery time, etc.

\section{Conclusions}

In order to develop their business and survive in the market, production SMEs must constantly satisfy the customers of their products. Increasing customer satisfaction may lead to increased profits, which is important for the sustainability of SMEs.

The paper contributes to creating a BPM management model that improves the art's current state on methodological and substantive bases with two contributions: integrating new information and using artificial intelligence techniques. The proposed model is used to find out whether it is possible to determine the link between the BPM success, which depends on the KPIs of business processes, and customer satisfaction. Therefore, on the basis of calculated weights and values of KPIs, RBMPS ratings for each process within each enterprise are obtained. On the other hand, there are ratings of the indicators of customer satisfaction (RICS), within each enterprise. Using ANN and GA the links between these two types of ratings are discovered and optimal solutions of RBMPS are proposed while maximizing the RICS values. So, by improving the values of KPIs, RBMPS ratings will be improved, which should lead to the improvement of RICS values, i.e., customer satisfaction.

The results provide evidence on how to separate the different performance dimensions to identify a direction for improvement of customer satisfaction. There were two primary scientific objectives. The first objective was to develop a model for assessing the process KPIs and customer satisfaction RICS indices from various aspects. The second objective was to develop an optimization model to support the decision-making process and to make optimal decisions to improve individual process KPIs based on RICS desired levels. Accordingly, a mathematical model with an accompanying 17-step algorithm was proposed.

The first part of the algorithm refers to determining ratings of BPM success and RICS values. This is done by a fuzzy mathematical model where existing uncertainties and imprecisions are modeled by TIFNs. These numbers are used in the proposed model because they present a good way of modeling human thinking. Since the issue of determining the weights of KPIs is stated as a multi-criteria decision-making problem, fuzzy AHP approach and fuzzy averaging operator are used. Aggregated weights and normalized fuzzy ratings of KPIs are used to obtain ratings of BPM success for each process in each SME. On the other hand, fuzzy ratings of ICS values in each enterprise were normalized and then defuzzified using the fuzzy algebra rules.

The second part of the algorithm uses ANN and GA approaches to determine the optimal scalar ratings of BPM success for each process within an SME. A two-layered BP ANN is used to calculate appropriate weights and biases. They are then used in GA in order to determine the optimal RBPMS for each process. The goal is to achieve the highest possible scores for all RICS at once. Based on these results, it is possible to determine the gaps between current and optimal ratings and to propose optimal improvements for each SME. This is very important for SMEs operating in today's changing environment.

The algorithm was tested on the data from 30 manufacturing SMEs operating in Serbia. It has been shown that there is a significant relationship between the observed business processes and ICSs. This allows the determination of the optimal level of improvements of business processes in an exact manner. Based on the obtained results, some of the methods for the business processes improvement are explained, which should lead to the improvement of customer satisfaction.

The proposed algorithm is very flexible. It allows the observation of a large number of SMEs, their business processes, KPIs, and ICS simultaneously. This is very important to obtain the most accurate results since they largely depend on the number of observed 
SMEs and entered values. Additionally, having data from different companies enables benchmarking, meaning that each company could compare their results with the results of other companies.

The practical implications include determining a decision support system that will enable the adoption of optimal decisions by the SMEs management team to improve the values of the process KPIs and customer satisfaction. The presented system may enable benchmarking, simulation, and verification of different scenarios to improve the process KPIs' and customer satisfaction RICS values of the SMEs.

The originality of the research lies in the presented two-part model that can be made available to SMEs and serve as a basis for determining future strategic directions.

However, collecting data from companies is not always an easy task, as they are not always willing to provide information. Furthermore, as in many genuine problems, the main disadvantage of the proposed model is obtaining input data of maximal accuracy because they depend strictly on the knowledge and the experience of the decision-makers. Besides, there is also a risk of their subjectivity when filling in the data.

Future works could test the developed methodology in other industrial branches, with other KPIs or ICS. Additionally, different types of ANN and optimization constraints could be applied.

Author Contributions: Conceptualization, M.Z.D.; A.D. and M.M.; methodology, M.Z.D.; software, A.D.; validation, M.Z.D. and A.D.; formal analysis, M.Z.D.; investigation, M.Z.D.; resources, M.Z.D.; data curation, M.Z.D.; writing-original draft preparation, M.Z.D.; writing-review and editing, M.M.; visualization, M.Z.D.; supervision, E.K.; project administration, E.K.; funding acquisition, E.K. All authors have read and agreed to the published version of the manuscript.

Funding: This research was partially done by Peter the Great St. Petersburg Polytechnic University and supported under the strategic academic leadership program 'Priority 2030' of the Russian Federation (Agreement 075-15-2021-1333 dated 30.09.2021).

Institutional Review Board Statement: Not applicable.

Informed Consent Statement: Not applicable.

Conflicts of Interest: The authors declare no conflict of interest.

\section{Appendix A}

Table A1. Assessments of the KPIs' values for the procurement process.

\begin{tabular}{|c|c|c|c|c|c|c|c|c|c|c|c|c|c|c|c|c|c|c|c|c|c|c|c|c|c|c|c|c|c|c|}
\hline & $e_{1}$ & $e_{2}$ & $e_{3}$ & $e_{4}$ & $e_{5}$ & $e_{6}$ & $e_{7}$ & $e_{8}$ & $e_{9}$ & $e_{10}$ & $e_{11}$ & $e_{12}$ & $e_{13}$ & $e_{14}$ & $e_{15}$ & $e_{16}$ & $e_{17}$ & $e_{18}$ & $e_{19}$ & $e_{20}$ & $e_{21}$ & $e_{22}$ & $e_{23}$ & $e_{24}$ & $e_{25}$ & $e_{26}$ & $e_{27}$ & $e_{28}$ & $e_{29}$ & 30 \\
\hline$i_{1}$ & $\widetilde{v}_{6}$ & $\widetilde{v}_{6}$ & $\widetilde{v}_{6}$ & $\widetilde{v}_{5}$ & $\widetilde{v}_{5}$ & $\widetilde{v}_{5}$ & $\widetilde{v}_{5}$ & $\widetilde{v}_{6}$ & $\widetilde{v}_{6}$ & $\widetilde{v}_{6}$ & $\widetilde{v}_{6}$ & $\widetilde{v}_{5}$ & $\widetilde{v}_{4}$ & $\widetilde{v}_{3}$ & $\widetilde{v}_{4}$ & $\widetilde{v}_{5}$ & $\widetilde{v}_{3}$ & $\widetilde{v}_{3}$ & $\widetilde{v}_{5}$ & $\widetilde{v}_{4}$ & $\widetilde{\widetilde{v}}_{2}$ & $\widetilde{v}_{3}$ & $\widetilde{v}_{4}$ & $\widetilde{v}_{6}$ & $\widetilde{v}_{4}$ & $\widetilde{v}_{4}$ & $\widetilde{v}_{5}$ & $\widetilde{v}_{4}$ & $\widetilde{v}_{4}$ & 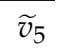 \\
\hline$i_{2}$ & $\widetilde{v}_{1}$ & $\widetilde{v}_{2}$ & $\widetilde{v}_{2}$ & $\widetilde{v}_{2}$ & $\widetilde{v}_{1}$ & $\widetilde{v}_{1}$ & $\widetilde{v}_{2}$ & $\widetilde{v}_{2}$ & $\widetilde{v}_{2}$ & $\widetilde{v}_{1}$ & $\widetilde{v}_{2}$ & $\widetilde{v}_{3}$ & $\widetilde{v}_{3}$ & $\widetilde{v_{3}}$ & $\widetilde{v}_{3}$ & $\widetilde{v}_{2}$ & $\widetilde{v}_{3}$ & $\widetilde{v}_{4}$ & $\widetilde{v}_{2}$ & $\widetilde{v}_{2}$ & $\widetilde{v}_{3}$ & $\widetilde{v}_{3}$ & $\widetilde{v}_{3}$ & $\widetilde{v}_{1}$ & $\widetilde{v}_{2}$ & $\widetilde{v}_{3}$ & $\widetilde{v}_{3}$ & $\widetilde{v}_{3}$ & $\widetilde{v}_{3}$ & $\tilde{v}_{3}$ \\
\hline$i_{3}$ & $\widetilde{v}_{1}$ & $\widetilde{v}_{2}$ & $\widetilde{v}_{1}$ & $\widetilde{v}_{2}$ & $\widetilde{v}_{2}$ & $\widetilde{v}_{2}$ & $\widetilde{v}_{2}$ & $\widetilde{v}_{2}$ & $\widetilde{v}_{1}$ & $\widetilde{v}_{1}$ & $\widetilde{v}_{1}$ & $\widetilde{v}_{3}$ & $\widetilde{v}_{3}$ & $\widetilde{v}_{3}$ & $\widetilde{v}_{3}$ & $\widetilde{v}_{2}$ & $\widetilde{v}_{3}$ & $\widetilde{v}_{3}$ & $\widetilde{v}_{2}$ & $\widetilde{v}_{3}$ & $\widetilde{v}_{3}$ & $\widetilde{v}_{3}$ & $\widetilde{v}_{2}$ & $\widetilde{v}_{1}$ & $\widetilde{v}_{2}$ & $\widetilde{v}_{3}$ & $\widetilde{v}_{3}$ & $\widetilde{v}_{2}$ & $\widetilde{v}_{3}$ & $\theta_{3}$ \\
\hline$i_{4}$ & $\widetilde{v}_{1}$ & $\widetilde{v}_{2}$ & $\widetilde{v}_{2}$ & $\widetilde{v}_{2}$ & $\widetilde{v}_{1}$ & $\widetilde{v}_{2}$ & $\widetilde{v}_{2}$ & $\widetilde{v}_{2}$ & $\widetilde{v}_{2}$ & $\widetilde{v}_{1}$ & $\widetilde{v}_{1}$ & $\widetilde{v}_{3}$ & $\widetilde{v}_{2}$ & $\widetilde{v}_{2}$ & $\widetilde{v}_{3}$ & $\widetilde{v}_{2}$ & $\widetilde{v}_{3}$ & $\widetilde{v}_{3}$ & $\widetilde{v}_{2}$ & $\sigma_{2}$ & $v_{4}$ & $v_{3}$ & $0_{3}$ & $v_{2}$ & $v_{2}$ & $v_{3}$ & $v_{3}$ & $v_{3}$ & $\widetilde{v}_{3}$ & \\
\hline$i_{5}$ & $\widetilde{v}_{2}$ & $\mathrm{o}_{2}$ & $\widetilde{v}_{2}$ & $\widetilde{v}_{3}$ & $\widetilde{v}_{2}$ & $\widetilde{v}_{3}$ & $\widetilde{v}_{2}$ & $\widetilde{v}_{2}$ & $\widetilde{v}_{1}$ & $\widetilde{v}_{1}$ & $\widetilde{v}_{2}$ & $\widetilde{v}_{2}$ & $\widetilde{71}$ & $\widetilde{v}$ & $\widetilde{v}_{2}$ & $\widetilde{v}_{2}$ & $\widetilde{v}_{3}$ & $\widetilde{v}_{3}$ & $\widetilde{v}_{2}$ & $\mathrm{O}_{2}$ & $\sigma_{3}$ & $0_{4}$ & $\widetilde{v}_{4}$ & $\widetilde{v}_{2}$ & $\widetilde{v}_{2}$ & $\widetilde{v}_{3}$ & 2 & 3 & $\widetilde{v}_{3}$ & \\
\hline
\end{tabular}

Table A2. Assessments of the KPIs' values for the production process.

\begin{tabular}{|c|c|c|c|c|c|c|c|c|c|c|c|c|c|c|c|c|c|c|c|c|c|c|c|c|c|c|c|c|c|c|}
\hline & $e_{1}$ & $e_{2}$ & $e_{3}$ & $e_{4}$ & $e_{5}$ & $e_{6}$ & $e_{7}$ & $e_{8}$ & $e_{9}$ & $e_{10}$ & $e_{11}$ & $e_{12}$ & $e_{13}$ & $e_{14}$ & $e_{15}$ & $e_{16}$ & $e_{17}$ & $e_{18}$ & $e_{19}$ & $e_{20}$ & $e_{21}$ & $e_{22}$ & $e_{23}$ & $e_{24}$ & $e_{25}$ & $e_{26}$ & $e_{27}$ & $e_{28}$ & $e_{29}$ & $e_{30}$ \\
\hline$i_{1}$ & $\widetilde{v}_{1}$ & $\widetilde{v}_{1}$ & $\widetilde{v}_{1}$ & $\widetilde{v}_{1}$ & $\widetilde{v}_{2}$ & $\widetilde{v}_{1}$ & $\widetilde{v}_{1}$ & $\widetilde{v}_{1}$ & $\widetilde{v}_{1}$ & $\widetilde{v}_{1}$ & $\widetilde{v}_{2}$ & $\widetilde{v}_{2}$ & $\widetilde{v}_{2}$ & $\widetilde{v}_{2}$ & $\widetilde{v}_{2}$ & $\widetilde{v}_{2}$ & $\widetilde{v}_{3}$ & $\widetilde{v}_{3}$ & $\widetilde{v}_{2}$ & $\widetilde{v}_{3}$ & $\widetilde{v}_{2}$ & $\widetilde{v}_{2}$ & $\widetilde{v}_{1}$ & $\widetilde{v}_{1}$ & $\widetilde{v}_{2}$ & $\widetilde{v}_{1}$ & $\widetilde{v}_{1}$ & $\widetilde{v}_{1}$ & 1 & $\widetilde{v}_{3}$ \\
\hline$i_{2}$ & $\widetilde{v}_{1}$ & $\widetilde{v}_{1}$ & $\widetilde{v}_{1}$ & $\widetilde{v}_{2}$ & $\widetilde{v}_{2}$ & $\widetilde{v}_{2}$ & $\widetilde{v}_{1}$ & $\widetilde{v}_{1}$ & $\widetilde{v}_{1}$ & $\widetilde{v}_{1}$ & $\widetilde{v}_{3}$ & $\widetilde{v}_{3}$ & $\widetilde{v}_{2}$ & $\widetilde{v}_{3}$ & $\widetilde{v}_{2}$ & $\widetilde{v}_{3}$ & $\widetilde{v}_{3}$ & $\widetilde{v}_{3}$ & $\widetilde{v}_{2}$ & $\widetilde{v}_{3}$ & $\widetilde{v}_{3}$ & $\widetilde{v}_{3}$ & $\widetilde{v}_{2}$ & $\widetilde{v}_{2}$ & $\widetilde{v}_{2}$ & 02 & $\sigma_{2}$ & $\sigma_{1}$ & 2 & $\widetilde{v}_{3}$ \\
\hline$i_{3}$ & $\widetilde{v}_{7}$ & $\widetilde{v}_{6}$ & $\widetilde{v}_{6}$ & $\widetilde{v}_{5}$ & $\widetilde{v}_{5}$ & $\widetilde{v}_{6}$ & $\widetilde{v}_{6}$ & $\widetilde{v}_{6}$ & $\widetilde{v}_{6}$ & $\widetilde{v}_{7}$ & $\widetilde{\pi 1-}$ & $\widetilde{z_{1}}$ & $\widetilde{\pi}$ & $\widetilde{v}_{4}$ & $\widetilde{v}_{5}$ & $\widetilde{v}_{6}$ & $\widetilde{v}_{4}$ & $\widetilde{v}_{4}$ & $\widetilde{v}_{6}$ & $\widetilde{v}_{5}$ & $\widetilde{v}_{4}$ & $\widetilde{v}_{5}$ & $\widetilde{v}_{5}$ & 0 & 3 & 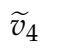 & $\widetilde{v}_{6}$ & $\widetilde{v}_{5}$ & $\widetilde{v}_{5}$ & $\widetilde{v}_{3}$ \\
\hline$i_{4}$ & $\widetilde{v}_{1}$ & $\widetilde{v}_{1}$ & $\widetilde{v}_{2}$ & $\widetilde{v}_{2}$ & $\widetilde{v}_{2}$ & $\widetilde{v}_{2}$ & $\widetilde{z_{1}}$ & $\widetilde{v}_{1}$ & $\widetilde{v}_{1}$ & $\widetilde{v}_{1}$ & $\widetilde{v}_{3}$ & $\widetilde{v}_{3}$ & $\widetilde{v}_{2}$ & $\widetilde{v}_{3}$ & $\widetilde{v}_{2}$ & $\widetilde{v}_{3}$ & $\widetilde{v}_{3}$ & $\widetilde{v}_{3}$ & $\widetilde{v}_{2}$ & $\widetilde{v}_{3}$ & $\widetilde{v}_{3}$ & $\widetilde{v}_{3}$ & $\widetilde{v}_{3}$ & $\widetilde{\pi_{1}}$ & $\widetilde{v}_{2}$ & $\widetilde{\pi_{0}}$ & $\widetilde{\pi \pi_{1}}$ & 2 & 6 & $\widetilde{v}_{3}$ \\
\hline$i_{-}$ & $\widetilde{v}_{1}$ & $\widetilde{v}_{1}$ & $\widetilde{\pi_{1}}$ & $\widetilde{\pi x_{1}}$ & $\widetilde{7 \pi}$ & $\widetilde{\pi_{0}}$ & $\widetilde{\pi 7}$ & $\widetilde{T}$ & $\widetilde{\pi_{1}}$ & $\widetilde{T}$ & $\widetilde{\tau}$ & $\widetilde{T}$ & $\widetilde{\tau}$ & $\widetilde{\tau}$ & $\widetilde{T}$ & $\widetilde{\tau}$ & $\widetilde{v}_{3}$ & $\widetilde{v}_{4}$ & $\widetilde{T}$ & $\widetilde{v}_{3}$ & $\widetilde{v}_{3}$ & & & & $\widetilde{v}_{2}$ & $\widetilde{v}_{2}$ & $\widetilde{v}_{2}$ & $\widetilde{v}_{2}$ & $\widetilde{v}_{2}$ & \\
\hline
\end{tabular}


Table A3. Assessments of the KPIs' values for the marketing and sales process.

\begin{tabular}{|c|c|c|c|c|c|c|c|c|c|c|c|c|c|c|c|c|c|c|c|c|c|c|c|c|c|c|c|c|c|c|}
\hline & & & & & & & & & & & $e_{11}$ & $\epsilon$ & 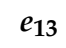 & 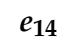 & $e_{15}$ & $e_{16}$ & $e_{17}$ & $e_{18}$ & $e_{19}$ & $e_{20}$ & $e_{21}$ & $e_{22}$ & $e_{23}$ & $e_{24}$ & $e_{25}$ & $e_{26}$ & $e_{27}$ & $e_{28}$ & 29 & \\
\hline$l$ & & & $\widetilde{v}_{5}$ & & & & $\gamma_{6}$ & & & & 0 & o & $0_{5}$ & 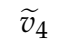 & $\widetilde{v}_{5}$ & & 1 & $\widetilde{v}_{4}$ & o & & & $\widetilde{v}_{5}$ & & & & & & $\widetilde{v}_{5}$ & & \\
\hline$i_{2}$ & 0 & b & 05 & 4 & $\widetilde{v}_{4}$ & $\widetilde{v}_{4}$ & $\widetilde{v}_{5}$ & $0_{6}$ & $\sigma_{G}$ & 0 & 0 & $\widetilde{v}_{5}$ & $0_{4}$ & $\widetilde{v}_{4}$ & 0 & $0_{6}$ & $0_{4}$ & $0_{4}$ & $u_{5}$ & $v_{4}$ & $\widetilde{v}_{5}$ & $0_{4}$ & $v_{4}$ & 05 & 4 & 04 & 5 & $5_{4}$ & $\widetilde{v}_{5}$ & \\
\hline$i$ & $\widetilde{v}_{2}$ & $v_{2}$ & $\widetilde{v}_{2}$ & 1 & $v_{2}$ & $v_{2}$ & $v_{2}$ & $\mathrm{U}_{2}$ & $\mathrm{U}_{2}$ & 0 & $v_{2}$ & $\widetilde{v}_{3}$ & $\widetilde{v}_{2}$ & $\widetilde{v}_{3}$ & $u_{2}$ & ${ }_{1}$ & $v_{2}$ & $\widetilde{v}_{3}$ & $u_{2}$ & $v_{2}$ & $u_{2}$ & $\widetilde{v}_{5}$ & 1 & ${ }_{1}$ & 02 & $v_{3}$ & 02 & 3 & 1 & \\
\hline$i_{4}$ & $u_{1}$ & $\mathrm{O}_{2}$ & $\mathrm{U}_{2}$ & 3 & $\widetilde{v}_{3}$ & $\widetilde{v}_{3}$ & $\widetilde{v}_{2}$ & $\widetilde{v}_{2}$ & $\widetilde{v}_{2}$ & $\widetilde{v}_{2}$ & $v_{2}$ & $\widetilde{v}_{3}$ & $\widetilde{v}_{3}$ & 03 & 02 & $\widetilde{v}_{2}$ & $\widetilde{v}_{2}$ & $\widetilde{v}_{2}$ & $v_{1}$ & $\widetilde{v}_{2}$ & $\widetilde{v}_{3}$ & $\widetilde{v_{3}}$ & $v_{3}$ & $\widetilde{v}_{2}$ & $\widetilde{v}_{3}$ & $u_{3}$ & $\widetilde{v}_{2}$ & $\widetilde{v}_{3}$ & $\widetilde{\sim}$ & \\
\hline$i_{5}$ & $\widetilde{v}_{6}$ & $\widetilde{v}_{6}$ & $\sigma_{6}$ & $\widetilde{\sim}$ & $\widetilde{v}_{5}$ & $\widetilde{\tau}$ & $\sigma_{6}$ & $\widetilde{v}_{6}$ & $\widetilde{v}_{5}$ & 07 & $\widetilde{v}_{5}$ & $\widetilde{v}_{5}$ & $\widetilde{v}_{4}$ & $\widetilde{v}_{5}$ & $\widetilde{v}_{5}$ & $\widetilde{v}_{6}$ & $\widetilde{\tau}$ & $\widetilde{v}_{3}$ & $\widetilde{v}_{5}$ & $\widetilde{v}_{5}$ & $\widetilde{v}_{5}$ & $\widetilde{v}_{5}$ & $\widetilde{v}_{4}$ & $\widetilde{v}_{6}$ & $\widetilde{v}_{5}$ & $\widetilde{v}_{4}$ & $u_{5}$ & $u_{5}$ & $\sigma_{6}$ & \\
\hline & & & & & & & & & & & & & & & & & & & & & & & & & & $\widetilde{v}_{1}$ & $\widetilde{v}_{2}$ & $\widetilde{v}_{2}$ & & \\
\hline
\end{tabular}

Table A4. Assessments of the KPIs' values for the after-sales service process.

\begin{tabular}{llllllllllllllllllllllllllllllll}
\hline & $e_{1}$ & $e_{2}$ & $e_{3}$ & $e_{4}$ & $e_{5}$ & $e_{6}$ & $e_{7}$ & $e_{8}$ & $e_{9}$ & $e_{10}$ & $e_{11}$ & $e_{12}$ & $e_{13}$ & $e_{14}$ & $e_{15}$ & $e_{16}$ & $e_{17}$ & $e_{18}$ & $e_{19}$ & $e_{20}$ & $e_{21}$ & $e_{22}$ & $e_{23}$ & $e_{24}$ & $e_{25}$ & $e_{26}$ & $e_{27}$ & $e_{28}$ & $e_{29}$ & $e_{30}$ \\
\hline$i_{1}$ & $\widetilde{v}_{5}$ & $\widetilde{v}_{5}$ & $\widetilde{v}_{4}$ & $\widetilde{v}_{4}$ & $\widetilde{v}_{4}$ & $\widetilde{v}_{4}$ & $\widetilde{v}_{4}$ & $\widetilde{v}_{5}$ & $\widetilde{v}_{4}$ & $\widetilde{v}_{5}$ & $\widetilde{v}_{6}$ & $\widetilde{v}_{5}$ & $\widetilde{v}_{5}$ & $\widetilde{v}_{4}$ & $\widetilde{v}_{5}$ & $\widetilde{v}_{5}$ & $\widetilde{v}_{4}$ & $\widetilde{v}_{4}$ & $\widetilde{v}_{5}$ & $\widetilde{v}_{4}$ & $\widetilde{v}_{2}$ & $\widetilde{v}_{3}$ & $\widetilde{v}_{4}$ & $\widetilde{v}_{5}$ & $\widetilde{v}_{4}$ & $\widetilde{v}_{4}$ & $\widetilde{v}_{5}$ & $\widetilde{v}_{4}$ & $\widetilde{v}_{5}$ & $\widetilde{v}_{3}$ \\
\hline$i_{2}$ & $\widetilde{v}_{3}$ & $\widetilde{v}_{3}$ & $\widetilde{v}_{2}$ & $\widetilde{v}_{2}$ & $\widetilde{v}_{2}$ & $\widetilde{v}_{2}$ & $\widetilde{v}_{3}$ & $\widetilde{v}_{3}$ & $\widetilde{v}_{3}$ & $\widetilde{v}_{3}$ & $\widetilde{v}_{4}$ & $\widetilde{v}_{3}$ & $\widetilde{v}_{3}$ & $\widetilde{v}_{3}$ & $\widetilde{v}_{3}$ & $\widetilde{v}_{3}$ & $\widetilde{v}_{3}$ & $\widetilde{v}_{3}$ & $\widetilde{v}_{4}$ & $\widetilde{v}_{3}$ & $\widetilde{v}_{2}$ & $\widetilde{v}_{4}$ & $\widetilde{v}_{4}$ & $\widetilde{v}_{5}$ & $\widetilde{v}_{3}$ & $\widetilde{v}_{3}$ & $\widetilde{v}_{3}$ & $\widetilde{v}_{3}$ & $\widetilde{v}_{4}$ & $\widetilde{v}_{3}$ \\
\hline$i_{3}$ & $\widetilde{v}_{2}$ & $\widetilde{v}_{2}$ & $\widetilde{v}_{3}$ & $\widetilde{v}_{3}$ & $\widetilde{v}_{3}$ & $\widetilde{v}_{3}$ & $\widetilde{v}_{1}$ & $\widetilde{v}_{2}$ & $\widetilde{v}_{2}$ & $\widetilde{v}_{1}$ & $\widetilde{v}_{1}$ & $\widetilde{v}_{2}$ & $\widetilde{v}_{2}$ & $\widetilde{v}_{3}$ & $\widetilde{v}_{2}$ & $\widetilde{v}_{2}$ & $\widetilde{v}_{3}$ & $\widetilde{v}_{3}$ & $\widetilde{v}_{2}$ & $\widetilde{v}_{3}$ & $\widetilde{v}_{5}$ & $\widetilde{v}_{4}$ & $\widetilde{v}_{3}$ & $\widetilde{v}_{2}$ & $\widetilde{v}_{3}$ & $\widetilde{v}_{3}$ & $\widetilde{v}_{3}$ & $\widetilde{v}_{3}$ & $\widetilde{v}_{3}$ & $\widetilde{v}_{4}$ \\
\hline$i_{4}$ & $\widetilde{v}_{5}$ & $\widetilde{v}_{5}$ & $\widetilde{v}_{4}$ & $\widetilde{v}_{3}$ & $\widetilde{v}_{3}$ & $\widetilde{v}_{3}$ & $\widetilde{v}_{4}$ & $\widetilde{v}_{4}$ & $\widetilde{v}_{4}$ & $\widetilde{v}_{5}$ & $\widetilde{v}_{5}$ & $\widetilde{v}_{4}$ & $\widetilde{v}_{4}$ & $\widetilde{v}_{3}$ & $\widetilde{v}_{4}$ & $\widetilde{v}_{5}$ & $\widetilde{v}_{3}$ & $\widetilde{v}_{3}$ & $\widetilde{v}_{4}$ & $\widetilde{v}_{3}$ & $\widetilde{v}_{2}$ & $\widetilde{v}_{2}$ & $\widetilde{v}_{4}$ & $\widetilde{v}_{5}$ & $\widetilde{v}_{3}$ & $\widetilde{v}_{3}$ & $\widetilde{v}_{4}$ & $\widetilde{v}_{3}$ & $\widetilde{v}_{3}$ & $\widetilde{v}_{2}$ \\
\hline
\end{tabular}

\section{Appendix B}

Table A5. Values of indicators of customer satisfaction.

\begin{tabular}{rlllllllllllllllllllllllllllll}
\hline $\boldsymbol{e}_{1}$ & $\boldsymbol{e}_{2}$ & $\boldsymbol{e}_{3}$ & $\boldsymbol{e}_{4}$ & $\boldsymbol{e}_{5}$ & $\boldsymbol{e}_{6}$ & $\boldsymbol{e}_{7}$ & $\boldsymbol{e}_{8}$ & $\boldsymbol{e}_{9}$ & $\boldsymbol{e}_{10}$ & $\boldsymbol{e}_{11}$ & $\boldsymbol{e}_{12}$ & $\boldsymbol{e}_{13}$ & $\boldsymbol{e}_{14}$ & $\boldsymbol{e}_{15}$ & $\boldsymbol{e}_{16}$ & $\boldsymbol{e}_{17}$ & $\boldsymbol{e}_{18}$ & $\boldsymbol{e}_{19}$ & $\boldsymbol{e}_{20}$ & $\boldsymbol{e}_{21}$ & $\boldsymbol{e}_{22}$ & $\boldsymbol{e}_{23}$ & $\boldsymbol{e}_{24}$ & $\boldsymbol{e}_{25}$ & $\boldsymbol{e}_{26}$ & $\boldsymbol{e}_{27}$ & $\boldsymbol{e}_{28}$ & $\boldsymbol{e}_{29}$ & $\boldsymbol{e}_{30}$ \\
\hline$I C S 1 \widetilde{v}_{6}$ & $\widetilde{v}_{6}$ & $\widetilde{v}_{5}$ & $\widetilde{v}_{5}$ & $\widetilde{v}_{4}$ & $\widetilde{v}_{4}$ & $\widetilde{v}_{6}$ & $\widetilde{v}_{5}$ & $\widetilde{v}_{5}$ & $\widetilde{v}_{6}$ & $\widetilde{v}_{5}$ & $\widetilde{v}_{4}$ & $\widetilde{v}_{5}$ & $\widetilde{v}_{4}$ & $\widetilde{v}_{5}$ & $\widetilde{v}_{6}$ & $\widetilde{v}_{4}$ & $\widetilde{v}_{4}$ & $\widetilde{v}_{6}$ & $\widetilde{v}_{4}$ & $\widetilde{v}_{4}$ & $\widetilde{v}_{4}$ & $\widetilde{v}_{5}$ & $\widetilde{v}_{6}$ & $\widetilde{v}_{4}$ & $\widetilde{v}_{3}$ & $\widetilde{v}_{4}$ & $\widetilde{v}_{4}$ & $\widetilde{v}_{5}$ & $\widetilde{v}_{4}$ \\
\hline$I C S \widetilde{v}_{6}$ & $\widetilde{v}_{6}$ & $\widetilde{v}_{6}$ & $\widetilde{v}_{5}$ & $\widetilde{v}_{5}$ & $\widetilde{v}_{5}$ & $\widetilde{v}_{6}$ & $\widetilde{v}_{6}$ & $\widetilde{v}_{5}$ & $\widetilde{v}_{6}$ & $\widetilde{v}_{6}$ & $\widetilde{v}_{5}$ & $\widetilde{v}_{6}$ & $\widetilde{v}_{4}$ & $\widetilde{v}_{5}$ & $\widetilde{v}_{6}$ & $\widetilde{v}_{4}$ & $\widetilde{v}_{4}$ & $\widetilde{v}_{6}$ & $\widetilde{v}_{4}$ & $\widetilde{v}_{4}$ & $\widetilde{v}_{5}$ & $\widetilde{v}_{6}$ & $\widetilde{v}_{7}$ & $\widetilde{v}_{4}$ & $\widetilde{v}_{4}$ & $\widetilde{v}_{5}$ & $\widetilde{v}_{4}$ & $\widetilde{v}_{6}$ & $\widetilde{v}_{4}$ \\
\hline$I C S 3 \widetilde{v}_{6}$ & $\widetilde{v}_{5}$ & $\widetilde{v}_{5}$ & $\widetilde{v}_{5}$ & $\widetilde{v}_{5}$ & $\widetilde{v}_{5}$ & $\widetilde{v}_{6}$ & $\widetilde{v}_{6}$ & $\widetilde{v}_{5}$ & $\widetilde{v}_{6}$ & $\widetilde{v}_{5}$ & $\widetilde{v}_{5}$ & $\widetilde{v}_{6}$ & $\widetilde{v}_{4}$ & $\widetilde{v}_{5}$ & $\widetilde{v}_{5}$ & $\widetilde{v}_{4}$ & $\widetilde{v}_{4}$ & $\widetilde{v}_{4}$ & $\widetilde{v}_{4}$ & $\widetilde{v}_{4}$ & $\widetilde{v}_{4}$ & $\widetilde{v}_{5}$ & $\widetilde{v}_{6}$ & $\widetilde{v}_{4}$ & $\widetilde{v}_{4}$ & $\widetilde{v}_{4}$ & $\widetilde{v}_{4}$ & $\widetilde{v}_{5}$ & $\widetilde{v}_{3}$ \\
\hline$I C S 4 \widetilde{v}_{5}$ & $\widetilde{v}_{5}$ & $\widetilde{v}_{5}$ & $\widetilde{v}_{6}$ & $\widetilde{v}_{4}$ & $\widetilde{v}_{4}$ & $\widetilde{v}_{4}$ & $\widetilde{v}_{5}$ & $\widetilde{v}_{5}$ & $\widetilde{v}_{6}$ & $\widetilde{v}_{4}$ & $\widetilde{v}_{4}$ & $\widetilde{v}_{4}$ & $\widetilde{v}_{4}$ & $\widetilde{v}_{6}$ & $\widetilde{v}_{6}$ & $\widetilde{v}_{4}$ & $\widetilde{v}_{4}$ & $\widetilde{v}_{5}$ & $\widetilde{v}_{4}$ & $\widetilde{v}_{4}$ & $\widetilde{v}_{4}$ & $\widetilde{v}_{5}$ & $\widetilde{v}_{6}$ & $\widetilde{v}_{4}$ & $\widetilde{v}_{4}$ & $\widetilde{v}_{4}$ & $\widetilde{v}_{4}$ & $\widetilde{v}_{6}$ & $\widetilde{v}_{3}$ \\
\hline
\end{tabular}

\section{Appendix C}

Table A6. Obtained Weights of KPIs for Each Process.

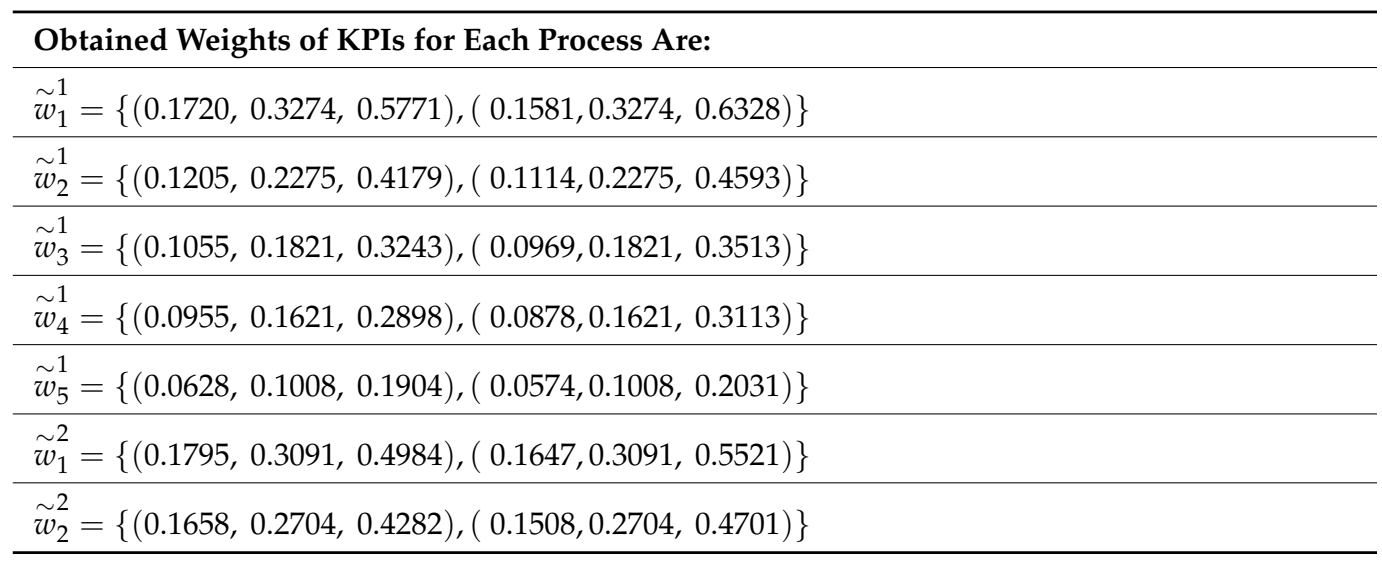


Table A6. Cont.

\section{Obtained Weights of KPIs for Each Process Are:}

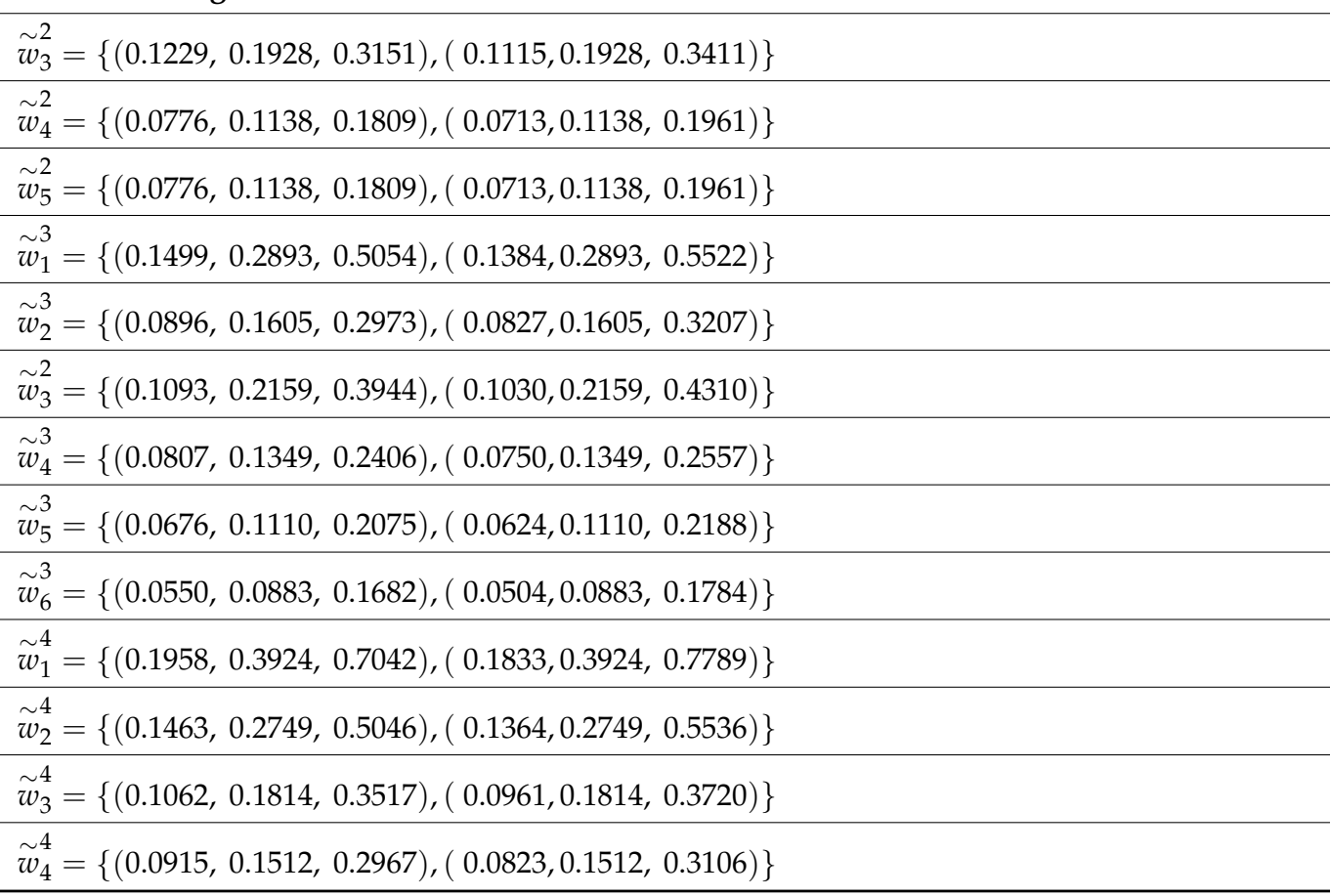

\section{Appendix D}

Table A7. Input data for defining optimization equations using ANN.

\begin{tabular}{|c|c|c|c|c|c|c|c|c|}
\hline & $p=1$ & $p=2$ & $p=3$ & $p=4$ & $I C S=1$ & $I C S=2$ & $I C S=3$ & $I C S=4$ \\
\hline$e=1$ & 0.1997 & 0.1994 & 0.1497 & 0.1833 & 0.88 & 0.88 & 0.88 & 0.72 \\
\hline$e=2$ & 0.1688 & 0.1965 & 0.1463 & 0.1833 & 0.88 & 0.88 & 0.72 & 0.72 \\
\hline$e=3$ & 0.1787 & 0.1898 & 0.1379 & 0.1271 & 0.72 & 0.88 & 0.72 & 0.72 \\
\hline$e=4$ & 0.1492 & 0.162 & 0.1304 & 0.1199 & 0.72 & 0.72 & 0.72 & 0.88 \\
\hline$e=5$ & 0.1784 & 0.146 & 0.1121 & 0.1159 & 0.56 & 0.72 & 0.72 & 0.56 \\
\hline$e=6$ & 0.1614 & 0.1687 & 0.1061 & 0.1199 & 0.56 & 0.72 & 0.72 & 0.56 \\
\hline$e=7$ & 0.1574 & 0.1965 & 0.1403 & 0.1705 & 0.88 & 0.88 & 0.88 & 0.56 \\
\hline$e=8$ & 0.1688 & 0.1965 & 0.1451 & 0.176 & 0.72 & 0.88 & 0.88 & 0.72 \\
\hline$e=9$ & 0.1842 & 0.1965 & 0.1417 & 0.1582 & 0.72 & 0.72 & 0.72 & 0.72 \\
\hline$e=10$ & 0.2052 & 0.1994 & 0.1673 & 0.1955 & 0.88 & 0.88 & 0.88 & 0.88 \\
\hline$e=11$ & 0.1875 & 0.1181 & 0.1428 & 0.2255 & 0.72 & 0.88 & 0.72 & 0.56 \\
\hline$e=12$ & 0.1122 & 0.1092 & 0.1198 & 0.176 & 0.56 & 0.72 & 0.72 & 0.56 \\
\hline$e=13$ & 0.1048 & 0.1301 & 0.1172 & 0.176 & 0.72 & 0.88 & 0.88 & 0.56 \\
\hline$e=14$ & 0.1095 & 0.1023 & 0.0978 & 0.1323 & 0.56 & 0.56 & 0.56 & 0.56 \\
\hline$e=15$ & 0.1003 & 0.137 & 0.1385 & 0.176 & 0.72 & 0.72 & 0.72 & 0.88 \\
\hline$e=16$ & 0.1574 & 0.1159 & 0.1647 & 0.1833 & 0.88 & 0.88 & 0.72 & 0.88 \\
\hline$e=17$ & 0.0803 & 0.0804 & 0.1128 & 0.1323 & 0.56 & 0.56 & 0.56 & 0.56 \\
\hline$e=18$ & 0.0745 & 0.0775 & 0.0995 & 0.1323 & 0.56 & 0.56 & 0.56 & 0.56 \\
\hline
\end{tabular}


Table A7. Cont.

\begin{tabular}{|c|c|c|c|c|c|c|c|c|}
\hline & $p=1$ & $p=2$ & $p=3$ & $p=4$ & $I C S=1$ & $I C S=2$ & $I C S=3$ & $I C S=4$ \\
\hline$e=19$ & 0.1574 & 0.1527 & 0.1489 & 0.1888 & 0.88 & 0.88 & 0.56 & 0.72 \\
\hline$e=20$ & 0.1312 & 0.0873 & 0.1295 & 0.1323 & 0.56 & 0.56 & 0.56 & 0.56 \\
\hline$e=21$ & 0.0762 & 0.1023 & 0.1257 & 0.0687 & 0.56 & 0.56 & 0.56 & 0.56 \\
\hline$e=22$ & 0.0777 & 0.1092 & 0.1207 & 0.1141 & 0.56 & 0.72 & 0.56 & 0.56 \\
\hline$e=23$ & 0.1038 & 0.1531 & 0.1392 & 0.1522 & 0.72 & 0.88 & 0.72 & 0.72 \\
\hline$e=24$ & 0.1909 & 0.1687 & 0.1592 & 0.2087 & 0.88 & 0.97 & 0.88 & 0.88 \\
\hline$e=25$ & 0.1455 & 0.146 & 0.1291 & 0.1323 & 0.56 & 0.56 & 0.56 & 0.56 \\
\hline$e=26$ & 0.0921 & 0.1551 & 0.1069 & 0.1323 & 0.39 & 0.56 & 0.56 & 0.56 \\
\hline$e=27$ & 0.1122 & 0.1687 & 0.1428 & 0.1574 & 0.56 & 0.72 & 0.56 & 0.56 \\
\hline$e=28$ & 0.1064 & 0.1763 & 0.1065 & 0.1323 & 0.56 & 0.56 & 0.56 & 0.56 \\
\hline$e=29$ & 0.0921 & 0.162 & 0.1472 & 0.1629 & 0.72 & 0.88 & 0.72 & 0.88 \\
\hline$e=30$ & 0.1249 & 0.0735 & 0.1075 & 0.1201 & 0.56 & 0.56 & 0.39 & 0.39 \\
\hline
\end{tabular}

\section{Appendix E}

Table A8. Hidden layer values of the parameters.

\begin{tabular}{ccccc}
\hline \multicolumn{3}{c}{ IW } & & b1 \\
\hline 1.5007 & -1.6309 & 0.86557 & 0.99701 & -2.4988 \\
\hline 1.226 & 1.3628 & -1.1437 & -1.3141 & -1.9081 \\
\hline-1.1365 & 1.7555 & 0.71124 & -1.0712 & 1.3724 \\
\hline 1.3059 & -0.29296 & 1.4443 & -1.315 & -0.93135 \\
\hline 1.4984 & 1.1729 & 0.55347 & -1.8375 & -0.67932 \\
\hline-1.3306 & -1.3533 & 0.75435 & 1.0208 & -0.72682 \\
\hline-1.0031 & -0.26165 & 1.1011 & 1.7896 & -0.35753 \\
\hline-0.20505 & 1.7655 & -0.73274 & -1.0372 & 1.6335 \\
\hline 1.3854 & 1.0058 & 0.21794 & 1.5918 & 1.8425 \\
\hline 1.1397 & 1.1896 & -1.0599 & -1.3549 & 2.6502 \\
\hline
\end{tabular}

Table A9. Output layer values of the parameters.

\begin{tabular}{ccccccccccccc}
\hline \multicolumn{10}{c}{ LW } & \multicolumn{1}{c}{ b2 } \\
\hline-0.13908 & -0.7086 & 0.49561 & 0.23919 & 0.3903 & -0.14243 & 0.258 & -0.42744 & 0.14419 & -0.33634 & -0.00906 \\
\hline 0.061347 & 0.11178 & 0.35141 & -0.09187 & 0.21791 & -0.44646 & 0.91944 & -0.21342 & -0.09013 & -0.53321 & 0.4686 \\
\hline 0.77751 & -0.31071 & -0.02863 & -0.4486 & 0.75258 & 0.5476 & -0.01411 & 0.45881 & 0.45256 & 0.022131 & 0.12332 \\
\hline 0.41696 & -0.02417 & 0.672 & 0.45597 & 0.051214 & 0.28033 & 0.26372 & 0.11978 & 0.20632 & -0.1249 & 0.20288 \\
\hline
\end{tabular}




\section{Appendix F}

Table A10. Optimal results. obtained by GA.

\begin{tabular}{cccccccc}
\hline Purchasing & Production & $\begin{array}{c}\text { Marketing } \\
\text { and Sales }\end{array}$ & $\begin{array}{c}\text { After Sales } \\
\text { Service } \\
\text { Process }\end{array}$ & $\begin{array}{c}\text { Degree of } \\
\text { Fulfillment of } \\
\text { Customer } \\
\text { Requirements }\end{array}$ & $\begin{array}{c}\text { Customer } \\
\text { Satisfaction } \\
\text { with Quality }\end{array}$ & $\begin{array}{c}\text { Customer } \\
\text { Customer } \\
\text { Loyalty }\end{array}$ & $\begin{array}{c}\text { Satisfaction with } \\
\text { the } \\
\text { Implementation } \\
\text { of the Contract }\end{array}$ \\
\hline 0.7586 & 0.4725 & 0.2599 & 0.2277 & 0.508906 & 0.718982 & 0.945718 & 0.969928 \\
\hline 0.3097 & 0.5117 & 0.1003 & 0.7245 & 0.382157 & 0.970195 & 0.449697 & 0.55818 \\
\hline 0.5141 & 0.3679 & 0.1819 & 0.7559 & 0.660412 & 0.965324 & 0.754372 & 0.496481 \\
\hline 0.3113 & 0.5099 & 0.1341 & 0.7264 & 0.598932 & 0.980704 & 0.574131 & 0.658281 \\
\hline 0.3101 & 0.5091 & 0.1131 & 0.7195 & 0.45391 & 0.979403 & 0.478917 & 0.598719 \\
\hline 0.3371 & 0.5151 & 0.1228 & 0.7406 & 0.403378 & 0.960478 & 0.570081 & 0.590135 \\
\hline 0.4766 & 0.4049 & 0.1043 & 0.6482 & 0.181812 & 0.946201 & 0.957059 & 0.547001 \\
\hline 0.4978 & 0.0634 & 0.3086 & 0.9457 & 0.832441 & 0.95707 & 0.828687 & 0.85103 \\
\hline 0.4976 & 0.1451 & 0.3559 & 0.9864 & 0.857691 & 0.948955 & 0.78133 & 0.899164 \\
\hline
\end{tabular}

\section{References}

1. Internal Market, Industry, Entrepreneurship and SMEs. Available online: https://ec.europa.eu/growth/smes/sme-definition_en (accessed on 4 December 2021).

2. Ministry of Economy of the Republic of Serbia. Report on Small and Medium Enterprises and Entrepreneurship for 2015 [in Serbian]; Ministry of Economy of the Republic of Serbia: Belgrade, Serbia, 2016.

3. Davis, R. It's the customer journey that counts. BPTrends Column. 2011. Available online: https://www.bptrends.com/bpt/wpcontent/publicationfiles/12-06-2011-COL-Processes\%20in\%20Practice-Customer\%20Journey-Davis-final.pdf (accessed on 5 October 2021).

4. Pavlić, D.; Ćukušić, M. Conceptualizing the convergence model of business process management and customer experience management. In International Conference on Business Process Management, Business Process Management: Blockchain and Central and Eastern Europe Forum, BPM 2019, Lecture Notes in Business Information Processing; Di Ciccio, C., Gabryelczyk, R., Garcia-Banuelos, L., Hernaus, T., Hull, R., Indihar Stemberger, M., Ko, A., Staples, M., Eds.; Springer: Cham, Switzerland, 2019; pp. 328-332. [CrossRef]

5. Kumar, V.; Smart, P.A.; Maddern, H.; Maull, R.S. Alternative perspectives on service quality and customer satisfaction: The role of BPM. Int. J. Serv. Ind. Manag. 2008, 19, 176-187. [CrossRef]

6. Chicu, D.; Pàmies, M.; Ryan, G.; Cross, C. Exploring the influence of the human factor on customer satisfaction in call centres. Bus. Res. Q. 2019, 22, 83-95. [CrossRef]

7. Kafetzopoulos, D.; Psomas, E. Organisational learning, non-technical innovation and customer satisfaction of SMEs. Int. J. Innov. Manag. 2016, 20, 1650041. [CrossRef]

8. International Organization for Standardization-ISO. ISO 9000:2015 Quality Management Systems-Fundamentals and Vocabulary. 2015. Available online: https://www.iso.org/obp/ui/\#iso:std:iso:9000:ed-4:v1:en (accessed on 5 October 2021).

9. Kaplan, R.S.; Norton, D.P. Strategy Maps: Converting Intangible Assets into Tangible Outcomes; Harvard Business School Press: Boston, MA, USA, 2004.

10. Sawang, S. Key performance indicators for innovation implementation: Perception vs. actual usage. Asia Pac. Manag. Rev. 2011, 16, 23-29. Available online: https:/ / eprints.qut.edu.au/28486/ (accessed on 5 October 2021).

11. El-Adly, M.I. Modelling the relationship between hotel perceived value, customer satisfaction, and customer loyalty. J. Retail. Consum. Serv. 2019, 50, 322-332. [CrossRef]

12. Sitorus, T.; Yustisia, M. The influence of service quality and customer trust toward customer loyalty: The role of customer satisfaction. Int. J. Qual. Res. 2018, 12, 639-654. [CrossRef]

13. Wayessa, Z.; Dabi, O.; Dida, G. Customers' satisfaction towards services provided by Bule Hora University, Ethiopia. Proc. Eng. Sci. 2021, 03, 217-230. [CrossRef]

14. Đorđević, M.Z.; Aleksić, A.; Puškarić, H. Application of Intuitionistic fuzzy numbers to determination of customer satisfaction in service enterprises (In Serbian). In Proceedings of the 46th National Conference on Quality, Kragujevac, Serbia, 29 May-1 June 2019; pp. 79-84. Available online: http://www.cqm.rs/2019/papers_fq/10.pdf (accessed on 6 October 2021).

15. Afthanorhan, A.; Awang, Z.; Rashid, N.; Foziah, H.; Ghazali, P. Assessing the effects of service quality on customer satisfaction. Manag. Sci. Lett. 2019, 9, 13-24. [CrossRef] 
16. Wu, C.C.; Liao, S.H.; Chen, Y.J.; Hsu, W.L. Service quality, brand image and price fairness impact on the customer satisfaction and loyalty. In Proceedings of the 2011 IEEE International Conference on Industrial Engineering and Engineering Management, Changchun, China, 3-5 November 2011; pp. 1160-1164. [CrossRef]

17. Anwar, S.; Min, L.; Dastagir, G. Effect of Service Quality, Brand Image, Perceived Value on Customer Satisfaction and Loyalty in the Chinese Banking Industry. Int. J. Bus. Econ. Manag. Work. 2019, 6, 24-30. Available online: http://www.ijbemw.com/paper/effectof-service-quality-brand-image-perceived-value-on-customer-satisfaction-and-loyalty-in-the-chinese-banking-industry (accessed on 10 October 2021).

18. Jain, E. Quality of services and customer loyalty: A study of private banks in NCT of Delhi through SERVQUAL. Proc. Eng. Sci. 2020, 2, 361-372. [CrossRef]

19. Anil, A.P.; Satish, K.P. Enhancing customer satisfaction through total quality management practices-An empirical examination. Total Qual. Manag. Bus. Excell. 2017, 30, 1528-1548. [CrossRef]

20. Goshime, Y.; Kitaw, D.; Jilcha, K. Lean manufacturing as a vehicle for improving productivity and customer satisfaction: A literature review on metals and engineering industries. Int. J. Lean Six Sigma 2019, 10, 691-714. [CrossRef]

21. Anil, A.P.; Satish, K.P. An empirical investigation of the relationship between TQM practices, quality performance, and customer satisfaction level. Int. J. Product. Qual. Manag. 2019, 26, 96. [CrossRef]

22. Xu, L.U.; Blankson, C.; Prybutok, V. Relative contributions of product quality and service quality in the automobile industry. Qual. Manag. J. 2017, 24, 21-36. [CrossRef]

23. Li, S.; Wunsch, D.C.; O'Hair, E.; Giesselmann, M.G. Comparative analysis of regression and artificial neural network models for wind turbine power curve estimation. J. Sol. Energy Eng. 2001, 123, 327-332. [CrossRef]

24. Zan, X.; Wu, Z.; Guo, C.; Yu, Z. A Pareto-based genetic algorithm for multi-objective scheduling of automated manufacturing systems. Adv. Mech. Eng. 2020, 12, 1687814019885294. [CrossRef]

25. Katoch, S.; Chauhan, S.S.; Kumar, V. A review on genetic algorithm: Past, present, and future. Multimed. Tools Appl. 2021, 80, 8091-8126. [CrossRef]

26. Holland, J.H. Adaptation in Natural and Artificial Systems: An Introductory Analysis with Applications to Biology, Control, and Artificial Intelligence; MIT Press: Cambridge, MA, USA; London, UK, 1992.

27. Štěpánek, J.; Št'ovíček, J.; Cimler, R. Application of genetic algorithms in stock market simulation. Procedia-Soc. Behav. Sci. 2012, 47, 93-97. [CrossRef]

28. Stravinskiene, I.; Serafinas, D. The link between business process management and quality management. J. Risk Financ. Manag. 2020, 13, 225. [CrossRef]

29. Pereira, J.L.; Freitas, A.P. Towards a characterisation of BPM tools' simulation support: The case of BPMN process models. Int. J. Qual. Res. 2019, 13, 783-796. [CrossRef]

30. Pan, W.; Wei, H. Research on key performance indicator (KPI) of business process. In Proceedings of the 2012 Second International Conference on Business Computing and Global Informatization, Shanghai, China, 12-14 October 2012. [CrossRef]

31. Parmenter, D. Key Performance Indicators: Developing, Implementing, and Using Winning KPIs, 3rd ed.; John Wiley \& Sons, Inc.: Hoboken, NJ, USA, 2015.

32. Wannes, A.; Ghannouchi, S.A. KPI-Based Approach for Business Process Improvement. Procedia Comput. Sci. 2019, 164, 265-270. [CrossRef]

33. Weinzierl, S.; Dunzer, S.; Zilker, S.; Matzner, M. Prescriptive business process monitoring for recommending next best actions. In International Conference on Business Process Management, Business Process Management Forum, BPM 2020, Lecture Notes in Business Information Processing; Fahland, D., Ghidini, C., Becker, J., Dumas, M., Eds.; Springer: Cham, Switzerland, 2020; pp. 193-209. [CrossRef]

34. Zadeh, L.A. The concept of a linguistic variable and its application to approximate reasoning-1. Inf. Sci. 1975, 8, 199-249. [CrossRef]

35. Dubois, D.; Prade, H. Fuzzy Sets and Systems: Theory and Applications; Academic Press: Boston, MA, USA, 1980.

36. Zimmermann, H.-J. Fuzzy Set Theory-And Its Applications, 4th ed.; Springer Science \& Business Media: New York, NY, USA, 2001.

37. Yüksel, I.; Dagdeviren, M. Using the fuzzy analytic network process (ANP) for Balanced Scorecard (BSC): A case study for a manufacturing firm. Expert Syst. Appl. 2010, 37, 1270-1278. [CrossRef]

38. Dožić, S.; Lutovac, T.; Kalić, M. Fuzzy AHP approach to passenger aircraft type selection. J. Air Transp. Manag. 2017, 68, 165-175. [CrossRef]

39. Metaxas, I.; Koulouriotis, D.; Spartalis, S. A multi-criteria model on calculating the Sustainable Business Excellence Index of a firm with fuzzy AHP and TOPSIS. Benchmarking Int. J. 2016, 23, 1522-1557. [CrossRef]

40. Kustiyahningsih, Y.; Rahmanita, E.; Purnama, J. Integration Balanced Scorecard and Fuzzy Analytic Network Process (FANP) for Measuring Performance of Small Medium Enterprise (SME). J. Theor. Appl. Inf. Technol. 2016, 94, 343-352.

41. Görener, A.; Ayvaz, B.; Kuşakcı, O.; Altınok, E. A hybrid type-2 fuzzy based supplier performance evaluation methodology: The Turkish Airlines technic case. Appl. Soft Comput. 2017, 56, 436-445. [CrossRef]

42. Abdullah, L.; Zulkifli, N. Integration of fuzzy AHP and interval type-2 fuzzy DEMATEL: An application to human resource management. Expert Syst. Appl. 2017, 42, 4397-4409. [CrossRef]

43. Mei, Y.; Xie, K. An improved TOPSIS method for metro station evacuation strategy selection in interval type-2 fuzzy environment. Clust. Comput. 2019, 22, 2781. [CrossRef] 
44. Komatina, N.; Djapan, M.; Ristić, I.; Aleksić, A. Fulfilling External Stakeholders' Demands—Enhancement Workplace Safety Using Fuzzy MCDM. Sustainability 2021, 13, 2892. [CrossRef]

45. Saini, N.; Bajaj, R.; Gandotra, N.; Dwivedi, R. Multi-criteria Decision Making with Triangular Intuitionistic Fuzzy Number based on Distance Measure \& Parametric Entropy Approach. Procedia Comput. Sci. 2018, 125, 34-41. [CrossRef]

46. Velu, L.G.N.; Selvaraj, J.; Ponnialagan, D. A New Ranking Principle for Ordering Trapezoidal Intuitionistic Fuzzy Numbers. Complexity 2017, 2017, 3049041. [CrossRef]

47. Prakash, K.A.; Suresh, M.; Vengataasalam, S. A new approach for ranking of intuitionistic fuzzy numbers using a centroid concept. Math. Sci. 2016, 10, 177-184. [CrossRef]

48. Nestić, S.; Đorđević, A.; Tadić, D.; Stefanović, M. A New Fuzzy Model for Evaluation of Key Performance Indicators and Purchasing Process Quality. In Proceedings of the 8th International Quality Conference, Kragujevac, Serbia, 23 May 2014; pp. 356-378.

49. Nestic, S.; Stefanovic, M.; Djordjevic, A.; Arsovski, S.; Tadic, D. A model of the assessment and optimisation of production process quality using the fuzzy sets and genetic algorithm approach. Eur. J. Ind. Eng. 2015, 9, 77-99. [CrossRef]

50. Nestic, S.; Djordjevic, A.; Puskaric, H.; Zahar Djordjevic, M.; Tadic, D.; Stefanovic, M. The evaluation and improvement of process quality by using the fuzzy sets theory and genetic algorithm approach. J. Intell. Fuzzy Syst. 2015, 29, 2017-2028. [CrossRef]

51. Tadic, D.; Aleksic, A.; Popovic, P.; Arsovski, S.; Castelli, A.; Joksimovic, D.; Stefanovic, M. The evaluation and enhancement of quality, environmental protection and seaport safety by using FAHP. Nat. Hazards Earth Syst. Sci. 2017, 17, 261-275. [CrossRef]

52. Tadić, D.; Đorđević, A.; Erić, M.; Stefanović, M.; Nestić, S. Two-step model for performance evaluation and improvement of New Service Development process based on fuzzy logics and genetic algorithm. J. Intell. Fuzzy Syst. 2017, 33, 3959-3970. [CrossRef]

53. Nestic, S.; Lampón, J.F.; Aleksic, A.; Cabanelas, P.; Tadic, D. Ranking manufacturing processes from the quality management perspective in the automotive industry. Expert Syst. 2019, 36, e12451. [CrossRef]

54. Boran, F.; Genç, S.; Kurt, M.; Akay, D. A multi-criteria intuitionistic fuzzy group decision making for supplier selection with TOPSIS method. Expert Syst. Appl. 2009, 36, 11363-11368. [CrossRef]

55. Atanassov, K.T. Intuitionistic Fuzzy Sets; ITKR's Scientific Session: Sophia, Bulgaria, 1983.

56. Djordjevic, M.Z.; Simeunovic, B.; Nestic, S.; Aleksic, A. Study on performance evaluation of the production process-fuzzy MCDM approach. J. Intell. Fuzzy Syst. 2020, 39, 4009-4026. [CrossRef]

57. Djordjevic, M.Z. Business Process Performance Management in Small and Medium-Sized Manufacturing Enterprises (in Serbian) Ph.D. Thesis; University of Kragujevac: Kragujevac, Serbia, 2020. Available online: https://nardus.mpn.gov.rs/handle/12345678 9/17541 (accessed on 2 October 2021).

58. Haykin, S.; Haykin, S. Neural Networks and Learning Machines; Prentice Hall/Pearson: New York, NY, USA, 2009.

59. Chi, M.; Zhao, J. Application of BP neural network in evaluating e-business performance for service industry. Int. J. Netw. Virtual Organ. 2021, 10, 374-385. Available online: https://ideas.repec.org/a/ids/ijnvor/v10y2012i3-4p374-385.html (accessed on 7 October 2021). [CrossRef]

60. Qi, S.; Jin, K.; Li, B.; Qian, Y. The exploration of internet finance by using neural network. J. Comput. Appl. Math. 2019, 369, 112630. [CrossRef]

61. Chen, L.; Jagota, V.; Kumar, A. Research on optimisation of scientific research performance management based on BP neural network. Int. J. Syst. Assur. Eng. Manag. 2021, 1-10. [CrossRef]

62. Xu, X.; Liu, F. Optimisation of online education and teaching evaluation system based on GA-BP neural network. Comput. Intell. Neurosci. 2021, 2021, 8785127. [CrossRef]

63. Al-Dmour, A.H.; Al-Dmour, R.H. Applying multiple linear regression and neural network to predict business performance using the reliability of accounting information system. Int. J. Corp. Financ. Account. 2018, 5, 12-26. [CrossRef]

64. Chen, R.; Yang, B.; Li, S.; Wang, S. A self-learning genetic algorithm based on reinforcement learning for flexible job-shop scheduling problem. Comput. Ind. Eng. 2020, 149, 106778. [CrossRef]

65. Zelenkov, Y.; Fedorova, E.; Chekrizov, D. Two-step classification method based on genetic algorithm for bankruptcy forecasting. Expert Syst. Appl. 2017, 88, 393-401. [CrossRef]

66. Chen, W.; Panahi, M.; Pourghasemi, H.R. Performance evaluation of GIS-based new ensemble data mining techniques of adaptive neuro-fuzzy inference system (ANFIS) with genetic algorithm (GA), differential evolution (DE), and particle swarm optimisation (PSO) for landslide spatial modelling. Catena 2017, 157, 310-324. [CrossRef]

67. Gacic, M.; Nestic, S.; Zahar Djordjevic, M.; Stefanovic, M. A Model for Ranking and Optimisation of Key Performance Indicators of the Strategy Process. Int. J. Ind. Eng. Manag. 2015, 6, 7-14.

68. Kaur, P. Selection of Vendor Based on Intuitionistic Fuzzy Analytical Hierarchy Process. Adv. Oper. Res. 2014, $2014,987690$. [CrossRef]

69. Saaty, T. The Analytic Hierarchy Process; McGraw-Hill International Book Co: New York, NY, USA, 1980.

70. Chang, D. Applications of the extent analysis method on fuzzy AHP. Eur. J. Oper. Res. 1996, 95, 649-655. Available online: https:/ / www.expertchoice.ir/wp-content/uploads/2017/08/FAHP-Chang-1996.pdf (accessed on 3 October 2021). [CrossRef]

71. Wang, Y.; Luo, Y.; Hua, Z. On the extent analysis method for fuzzy AHP and its applications. Eur. J. Oper. Res. 2008, 186, 735-747. Available online: https:/ /ideas.repec.org/a/eee/ejores/v186y2008i2p735-747.html (accessed on 5 October 2021). [CrossRef]

72. Banduka, N.; Tadić, D.; Mačužić, I.; Crnjac, M. Extended process failure mode and effect analysis (PFMEA) for the automotive industry: The FSQC-PFMEA. Adv. Prod. Eng. Manag. 2018, 13, 206-215. [CrossRef] 
73. Xiaoqiong, W.; Fang, P.; Shihuang, S.; Jianan, F. Trapezoidal Fuzzy AHP for the Comprehensive Evaluation of Highway Network Programming Schemes in Yangtze River Delta. In Proceedings of the Fifth World Congress on Intelligent Control and Automation, Hangzhou, China, 15-19 June 2004; pp. 5232-5236. [CrossRef]

74. Sadi-Nezhad, S.; Damghani, K.K. Application of a fuzzy TOPSIS method base on modified preference ratio and fuzzy distance measurement in assessment of traffic police centers performance. Appl. Soft Comput. 2010, 10, 1028-1039. [CrossRef]

75. Kahraman, C.; Öztayşi, B.; Sarı, İ.U.; Turanoğlu, E. Fuzzy analytic hierarchy process with interval type-2 fuzzy sets. Knowl.-Based Syst. 2014, 59, 48-57. [CrossRef]

76. Tadić, D.; Đorđević, A.; Aleksić, A.; Nestić, S. Selection of recycling centre locations by using the interval type-2 fuzzy sets and two-objective genetic algorithm. Waste Manag. Res. 2019, 37, 26-37. [CrossRef]

77. Sadiq, R.; Tesfamariam, S. Environmental decision-making under uncertainty using intuitionistic fuzzy analytic hierarchy process (IF-AHP). Stoch. Environ. Res. Risk Assess. 2009, 23, 75-91. [CrossRef]

78. Tavana, M.; Zareinejad, M.; Di Caprio, D.; Kaviani, M. An integrated intuitionistic fuzzy AHP and SWOT method for outsourcing reverse logistics. Appl. Soft Comput. 2016, 40, 544-557. [CrossRef]

79. Julie, N.; Uthra, G. Triangular intuitionistic fuzzy ahp and its application to select best product of notebook computer. Int. J. Pure Appl. Math. 2017, 113, 253-261.

80. Alipour, M.; Hafezi, R.; Ervural, B.; Kaviani, M.; Kabak, Ö. Long-term policy evaluation: Application of a new robust decision framework for Iran's energy exports security. Energy 2018, 157, 914-931. [CrossRef]

81. Abdullah, L.; Najib, L. Sustainable energy planning decision using the intuitionistic fuzzy analytic hierarchy process: Choosing energy technology in Malaysia. Int. J. Sustain. Energy 2015, 35, 360-377. [CrossRef]

82. Atanassov, K.; Pasi, G.; Yager, R. Intuitionistic fuzzy interpretations of multi-criteria multi-person and multi-measurement tool decision making. Int. J. Syst. Sci. 2005, 36, 859-868. [CrossRef]

83. Nayagam, V.L.G.; Jeevaraj, S.; Sivaraman, G. Complete Ranking of Intuitionistic Fuzzy Numbers. Fuzzy Inf. Eng. 2016, 8, 237-254. [CrossRef]

84. Nagoorgani, A.; Ponnalagu, K. A New Approach on Solving Intuitionistic Fuzzy Linear Programming Problem. Appl. Math. Sci. 2012, 6, 3467-3474

85. Li, D.; Nan, J.; Zhang, M. A Ranking Method of Triangular Intuitionistic Fuzzy Numbers and Application to Decision Making. Int. J. Comput. Intell. Syst. 2010, 3, 522-530. [CrossRef]

86. Lazic, M. Measurements, Analyses and Improvements (In Serbian); Faculty of Mechanical Engineering, Center for Quality: Kragujevac, Serbia, 2008

87. Larsson, A.; Broström, E. Ensuring customer retention: Insurers' perception of customer loyalty. Mark. Intell. Plan. 2019, 38, 151-166. [CrossRef] 